\title{
EL ACCESO A LA JUSTICIA AMBIENTAL A NIVEL COMUNITARIO Y EN ESPAÑA VEINTE AÑOS DESPUÉS DEL CONVENIO DE AARHUS
}

\section{ACCESS TO ENVIRONMENTAL JUSTICE IN THE EUROPEAN UNION AND SPAIN TWENTY YEARS AFTER THE AARHUS CONVENTION}

\author{
ÁNgel RUIZ dE APODACA ESPINOSA \\ Profesor titular de Derecho Administrativo \\ Universidad de Navarra \\ aruiz@unav.es
}

Recibido: 14 de mayo de 2018 / Aceptado: 28 de junio de 2018

RESUMEN: El acceso a la justicia ambiental constituye el tercer pilar del Convenio de Aarhus, el menos desarrollado legalmente tal y como acredita la ausencia de una normativa comunitaria y su escueta regulación en la legislación básica estatal. En el presente trabajo se ponen de manifiesto los principales obstáculos en el acceso a la justicia ambiental y la interpretación de tal derecho por parte de la jurisprudencia comunitaria y española.

RESUM: L'accés a la justícia ambiental constitueix el tercer pilar del Conveni d'Aarhus, el que menys s'ha desplegat legalment tal com acredita l'absència de normativa comunitària i la regulació concisa en la legislació bàsica estatal. En aquest treball es posen de manifest els principals obstacles en l'accés a la justícia ambiental i la interpretació d'aquest dret per part de la jurisprudència comunitària i espanyola.

ABSTRACT: Access to justice is the third pillar of the Aarhus Convention, the least developed, as evidenced by the absence of the european regulation and its limited regulation in the Spanish legislation. The main obstacles in the access to 
justice and the interpretation of this right by European and Spanish judges are analyzed in this work.

PALABRAS CLAVE: acceso a la justicia - legitimación - medio ambiente obstáculos.

PARAULES CLAU: Accés a la justícia - legitimació - medi ambient - obstacles.

KEY WORDS: Access to justice - requirements - environment - obstacles.

SUMARIO: I. Introducción. II. El Convenio de Aarhus y su previsión sobre el acceso a la justicia ambiental. III. La ausencia de normativa comunitaria en la materia y la concreción de este derecho por el TJUE. 1. La frustrada Propuesta de Directiva de acceso a la justicia de 2004. 2. La reciente Comunicación de la Comisión Europea sobre el acceso a la justicia ambiental. 3. Algunos pronunciamientos recientes del TJUE. IV. La previsión de la legislación básica estatal en materia de acceso a la justicia ambiental y el amplio reconocimiento de algunas leyes autonómicas.1. Las diferentes vías judiciales de defensa de los intereses ambientales. 2. Previsiones de la LIPPJMA en orden a la legitimación condicionada. 3. Las previsiones de la legislación autonómica en cuanto al acceso a la justicia ambiental: heterogeneidad y dudosa constitucionalidad no resuelta por la STC 151/2012. V. Los obstáculos al acceso a la justicia ambiental siguen siendo los mismos veinte años después: principalmente económicos. 1. La asunción de las costas procesales. 2. El necesario acceso a la justicia gratuita. 3. La batalla de las medidas cautelares. Cautelas y contracautelas que dificultan la justicia ambiental. VI. En conclusión. VII. Bibliografía.

\section{INTRODUCCIÓN}

Se cumplen ya veinte años del Convenio de Aarhus, sobre información participación y acceso a la justicia ambiental, los tres denominados principios de la democracia ambiental.

Como ya ha señalado la abundante doctrina relativa a este convenio y su desarrollo, el derecho a la información y el derecho de participación constituyen un binomio inseparable, y ambos derechos deben estar presentes en todas las actividades públicas que tengan una relación directa o indirecta con la protección ambiental. La garantía del cumplimiento de los citados derechos y de la legislación ambiental exige la posibilidad de acceso a la justicia frente a cualquier resolución o acto administrativo. 
El equilibrio entre los privilegios de la Administración ambiental y las garantías del ciudadano frente a su actuación encuentra su garantía absoluta en la posibilidad de este último de acudir a las instancias judiciales oportunas frente a cualquier vulneración de los derechos o intereses legítimos que, según el ordenamiento, le corresponde a dicha Administración tutelar, ya sea por inobservancia de los procedimientos o bien porque sustantivamente se adoptan decisiones que no casan con el deber de protección ambiental que la Constitución le encomienda.

$Y$ es que el derecho a disfrutar de un medio ambiente adecuado, reconocido en el artículo 45 de la Constitución, además de constituir un principio rector de la política social y económica, constituye un interés difuso, un interés colectivo, un derecho que afecta a otros muchos derechos, incluso fundamentales, reconocidos en nuestra Constitución ${ }^{1}$. De ahí que, además de que los poderes públicos estén obligados a velar por la utilización racional de los recursos naturales, suministrar información y favorecer la participación en la toma de decisiones ambientales, también deben cumplir con respeto escrupuloso la legislación ambiental y eventualmente someterse a las posibles acciones judiciales que los ciudadanos puedan entablar frente a ellos cuando entiendan que no han cumplido esas funciones de manera adecuada y con escrupuloso respeto a la legalidad ambiental vigente.

El vigésimo aniversario del Convenio de Aarhus nos permite hacer un breve análisis sobre su implementación, sobre los pasos que se han dado desde instancias europeas en su desarrollo y, particularmente, sobre los obstáculos en el ejercicio de los derechos que reconoce. He de decir, salvo mejor opinión, que en relación con el tercero de los pilares, el acceso a la justicia, las cosas no han cambiado mucho en estos veinte años, más allá de la concreción del ejercicio de este derecho a través de la jurisprudencia comunitaria y nacional, aunque se siguen dando pasos.

\footnotetext{
${ }^{1}$ Sobre la tutela de los intereses colectivos, cabe citar de manera destacada los recientes estudios: CARBONELL PORRAS, E., "Intereses colectivos en la jurisdicción contenciosoadministrativa", Intereses colectivos y legitimación activa, Aranzadi, Pamplona, 2014; PEÑALVER I CABRÉ, A., La defensa de los intereses colectivos en el contenciosoadministrativo, Aranzadi, Pamplona, 2016.
} 
A nivel de la Unión Europea, se sigue sin un instrumento jurídico-normativo que regule el acceso a la justicia ambiental, a diferencia de los aspectos de información y participación, que inmediatamente fueron desarrollados por sendas directivas. En España, como es sabido, la transposición de las antedichas directivas fue llevada a cabo por la denominada Ley Aarhus, la Ley 27/2006, de 18 de julio, por la que se regulan los derechos de acceso a la información, de participación pública y de acceso a la justicia en materia de medio ambiente (LIPPJMA, en lo sucesivo) ${ }^{2}$, que ya ha superado una década y que, además de desarrollar los derechos de información y participación, regula el acceso a la justicia ambiental, una regulación escueta que limita el acceso a la denominada acción pública a determinadas ONG que reúnan ciertos requisitos, pero que ya adelanto que a mi juicio es suficiente ${ }^{3}$.

En el presente trabajo se hará mención a la regulación del Convenio de Aarhus en materia de acceso a la justicia, a las iniciativas de la Unión Europea y, finalmente, mediante un análisis legal y jurisprudencial español, a los obstáculos en el acceso a la justicia.

\section{EL CONVENIO DE AARHUS Y SU PREVISIÓN SOBRE EL ACCESO A LA JUSTICIA AMBIENTAL}

Como es sabido, el 25 de julio de 1998, la Comisión Económica de las Naciones Unidas para Europa adoptó el Convenio sobre el acceso a la información, la participación del público en la toma de decisiones y el acceso a la justicia en materia de medio ambiente, conocido como Convenio de Aarhus, que entró en vigor el 30 de octubre de 2001, siendo ratificado por la Comunidad Europea mediante la Decisión del Consejo de 17 de febrero de 2005, y por España el 15 de diciembre de 2004, donde entró en vigor el 31 de marzo de $2005^{4}$.

\footnotetext{
2 Sobre esta ley, RAZQUIN LIZARRAGA, J. A. y RUIZ DE APODACA ESPINOSA, A., Información, participación y acceso a la justicia en materia de medio ambiente. Comentario sistemático a la Ley 27/2006, de 18 de julio, Aranzadi, Pamplona, 2007.

${ }^{3}$ En esto disiento de otros planteamientos; RUIZ DE APODACA ESPINOSA, A., "La acción pública ambiental: una necesidad parcialmente satisfecha por la Ley 27/2006, de 18 de julio", RADA, núm. 11, 2007; PEÑALVER i CABRÉ, A. "Novedades en el acceso a la justicia y a la tutela administrativa en asuntos ambientales", Pigrau Solé, A., Acceso a la información, participación pública y acceso a la justicia en materia de medio ambiente: diez años del Convenio de Aarhus, Atelier, Barcelona, 2008.

${ }^{4}$ Sobre la incidencia del Convenio de Aarhus particularmente en España, véase la obra colectiva PIGRAU SOLÉ, A. (dir.), Acceso a la información, participación pública y acceso a la justicia en materia de medio ambiente. Diez años del Convenio de Aarhus, Atelier, Barcelona, 2009.
} 
La regulación que del acceso a la justicia realiza el Convenio en su artículo 9. ${ }^{\circ}$ constituye el tercero de los pilares del Convenio de Aarhus ${ }^{5}$, junto a los de información y participación. El Convenio prevé la posibilidad de acceso a la justicia de los ciudadanos y ONG frente a decisiones de contenido ambiental, cubriendo en su artículo $9 .^{\circ}$ los supuestos siguientes de acceso a la justicia:

a) Frente a la vulneración del derecho a la información ambiental que el propio Convenio reconoce, otorga legitimación a todo solicitante ya sea en vía administrativa previa o judicial.

b) Frente a la vulneración del derecho de participación pública en la toma de decisiones de contenido ambiental que el propio Convenio reconoce, otorga legitimación a todo interesado que estime que su derecho de participación haya podido ser vulnerado, con especial referencia a las ONG ambientales.

c) Frente a las vulneraciones del derecho ambiental nacional realizadas por las autoridades nacionales o particulares, legitima a aquellos ciudadanos a los que se les reconozca legitimación con arreglo a su derecho interno.

Como se ve, el Convenio de Aarhus no solo prevé la posibilidad de interponer un recurso por vulneración de los derechos de información o participación, sino también la posibilidad de interponer una demanda o recurso por incumplimiento de las obligaciones ambientales. El Convenio, no obstante, remite al derecho interno de cada Estado, si bien requiere a los Gobiernos que garanticen el acceso a los procedimientos administrativos y judiciales para impugnar actos $u$ omisiones contrarios a la ley tanto de personas o de entidades privadas como de la Administración pública. Veremos que este reconocimiento no va a ser así en

\footnotetext{
${ }^{5}$ Sobre el concreto tercer pilar de acceso a la justicia del Convenio de Aarhus, entre otros, ECEIZABARRENA, X., "Participación y acceso a la justicia ambiental: el Convenio de Aarhus de 1998", RADA, núm. 1, 2002; GARCÍA URETA, A., "Aspectos sobre el acceso a la justicia en el Convenio de Aarhus y su incidencia en el Derecho comunitario", Ingurugiroa eta Zuzenbidea, núm. 3, IVAP-Bilbao, 2005; "El Convenio de Aarhus: derecho de participación y de acceso a la justicia", Magariños Compaired, A. (coord.), Derecho al conocimiento y acceso a la información en las políticas de medio ambiente, MAAP, Madrid, 2005; SANCHIS MORENO, F., Guía sobre el acceso a la Justicia Ambiental. Convenio de Aarhus, CGAE y AJA-ELAW España, 2007; PEÑALVER I CABRÉ, A., "Nuevos instrumentos para la aplicación de la legislación ambiental ante la inactividad administrativa (de las acciones ciudadanas (citizen suits) al Convenio de Aarhus)", RAP, 172, 2007, y "Novedades en el acceso a la justicia y la tutela administrativa en asuntos medioambientales", Pigrau Solé, A. (dir.), Acceso a la información, participación pública y acceso a la justicia en materia de medio ambiente: diez años del Convenio de Aarhus, Atelier, Barcelona, 2007; y SANCHIS MORENO, F., SALAZAR ORTUÑO, E. y RUIZ MACIÁ, G., Democracia ambiental y acceso a la justicia. La aplicación del Convenio de Aarhus en España, AJA y Fundación Biodiversidad, Madrid, 2009.
} 
nuestro derecho interno, lo que ha planteado ya algunos problemas también en su aplicación a la luz del Convenio ${ }^{6}$.

En cuanto al acceso a la justicia ambiental sin cortapisas, a juicio de LOPERENA, "se trata de una legitimación activa abierta a la ciudadanía, en aras de su imprescindible participación en la administración de la justicia, tratándose como es el caso ambiental de un bien común, escaso e insustituible para nuestro desarrollo como personas, cuya tutela judicial emana necesariamente de su afección al concepto de bien colectivo perteneciente a toda la comunidad"7. Veamos si ese acceso se garantiza de acuerdo con lo previsto en el Convenio de Aarhus y cuáles son los principales obstáculos.

\section{LA AUSENCIA DE NORMATIVA COMUNITARIA EN LA MATERIA Y LA CONCRECIÓN DE ESTE DERECHO POR EL TJUE}

\section{La frustrada Propuesta de Directiva de acceso a la justicia de 2004}

La política ambiental es una de las políticas principales de la UE y ha dado lugar a todo un ordenamiento jurídico ambiental muy profuso ${ }^{8}$.

El Convenio de Aarhus fue ratificado por la Comunidad Europea mediante Decisión del Consejo 2005/370/CE, de 17 de febrero de 2005, por lo que pasó a formar parte del acervo ambiental comunitario, informando y vinculando el desarrollo normativo y la práctica aplicativa de los Estados miembros al margen de la ratificación individual por esos Estados.

Pese a ello, la UE no ha desarrollado normativamente el tercer pilar del Convenio de Aarhus, a diferencia de los otros dos, los relativos a información y participación. El recurso del artículo 9.3 del Convenio de Aarhus ha sido solo previsto y desarrollado ante las instituciones comunitarias mediante el Reglamento 1367/2006 del Parlamento y del Consejo, de 6 de septiembre,

\footnotetext{
${ }^{6}$ A modo de ejemplo, JUSTE RUIZ, José y SALAZAR ORTUÑO, Eduardo, "Incumplimiento por parte de España de las obligaciones del convenio de Aarhus: comunicación ACCC/C/2008/24, el caso senda de Granada en Murcia", RADA, núm.18, 2010.

${ }^{7}$ LOPERENA ROTA, D. y BALLESTEROS PINILLA, G., "El ejercicio de acciones en el orden contencioso-administrativo en defensa del medio ambiente", Revista Jurídica de Castilla y León, núm. 26, 2012, p. 210.

${ }^{8}$ Cfr. PLAZA MARTíN, C., Derecho Ambiental de la Unión Europea, Tirant lo Blanch, Valencia, 2005.
} 
relativo a la aplicación, a las instituciones y a los organismos comunitarios, de las disposiciones del Convenio de Aarhus. Ahora bien, no ha habido un desarrollo que sea de aplicación a los Estados miembros con carácter uniforme, una necesidad en aras de hacer efectivo este tercer pilar ${ }^{9}$.

Actualmente, en la mayoría de los Estados miembros de la UE no existe una denominada acción pública en materia ambiental ${ }^{10}$. La mayoría de las legislaciones exigen una legitimación concreta, debiendo existir un interés directo entre el recurrente y la decisión recurrida. No obstante, buen número de Estados, aunque con diferencias, prevén la posibilidad de que las ONG ambientales tengan acceso a los tribunales ${ }^{11}$.

En cuanto a la exigencia del acceso a la justicia derivada del Convenio de Aarhus, ha habido algunas propuestas que no han llegado a cristalizar y que eran si cabe más restrictivas que, por ejemplo, la actual ley española. Un claro ejemplo de lo dicho lo constituyó la propuesta de Directiva del Parlamento Europeo y del Consejo sobre el acceso a la justicia en materia de medio ambiente de 24 de octubre de 2003 [COM (2003) 624, final] ${ }^{12}$.

Esta propuesta de Directiva quedó paralizada tras dos dictámenes favorables: el Dictamen en primera lectura del Parlamento Europeo, de 31 de marzo de 2004, si bien con algunas enmiendas ${ }^{13}$, y el Dictamen favorable del Comité Económico y Social Europeo, de 29 de abril de 2004, que manifestaba que el instrumento más conveniente del que dispone la Unión Europea para garantizar la aplicación

\footnotetext{
9 PEÑALVER I CABRÉ, A., "El derecho humano al medio ambiente y su protección efectiva", RVAP, núm. 99-100, 2014. p. 2350.

10 Sobre este particular en Alemania y Eslovaquia en concreto, ORTEGA BERNARDO, J., "¿Quién ha apostado por la efectiva implantación del derecho de acceso a la justicia a favor de las organizaciones no gubernamentales en defensa del medio ambiente?" Actualidad Jurídica Ambiental, núm. 6, 2011, pp.11-13.

${ }^{11}$ Cfr. EBBESSON, J., "Information, Participation and Access to Justice: the model of the Aarhus Convention", Joint UNEP-OHCHR Expert Seminar on Human Rights and the Environment, Background, Paper No. 5, Ginebra, 2002, pp. 23 y ss.

${ }^{12}$ Sobre esta frustrada propuesta, GONZÁLEZ BONDÍA, A., "La regulación comunitaria del acceso a la información, la participación pública y el acceso a la justicia en materia de medio ambiente en sus Estados miembros", Pigrau Solé, A. (dir.), Acceso a la información, participación pública y acceso a la justicia en materia de medio ambiente: diez años del Convenio de Aarhus, Atelier, Barcelona, 2007, pp.112-115.

${ }^{13}$ Enmiendas destinadas, en particular, a recordar el objetivo de la Convención de Aarhus, ampliar la capacidad procesal a las organizaciones locales o a las que promueven el desarrollo sostenible, precisar las modalidades de acceso a la justicia en materia medioambiental en el caso de los litigios transfronterizos y facilitar el ejercicio práctico del derecho a entablar acciones judiciales.
} 
de la legislación medioambiental es la implicación de los ciudadanos en la política del desarrollo sostenible.

El objetivo de la propuesta de Directiva era garantizar el acceso a la justicia en materia de medio ambiente a los miembros del público y a las denominadas entidades habilitadas, estableciendo una serie de requisitos de legitimación ${ }^{14}$ para el acceso a la justicia en el ámbito comunitario frente a las acciones y omisiones en materia ambiental.

Por último, esta breve propuesta de Directiva, en el mismo sentido que Aarhus, establecía que los procedimientos administrativos y judiciales previstos en la presente propuesta debían ser objetivos, eficaces, adecuados, equitativos, rápidos y no excesivamente caros. Transcurridos ya catorce años de este intento frustrado, no ha vuelto a darse ninguna otra iniciativa, siendo la regulación interna de cada uno de los Estados miembros la que ha determinado el ejercicio de este derecho con mayor o menor fidelidad a los compromisos derivados de la ratificación del Convenio de Aarhus.

\section{La reciente Comunicación de la Comisión Europea sobre el acceso a la justicia ambiental}

Pese a los frustrados intentos señalados, ninguna directiva o reglamento a nivel comunitario ha regulado, por lo tanto, el acceso a la justicia ambiental de forma que obligue a todos los Estados miembros de manera uniforme a adoptar una serie de medidas concretas. Ello evidencia un claro fracaso de la UE en lo que a la implementación del tercer pilar del Convenio de Aarhus se refiere.

El último y reciente intento en este sentido lo constituye la extensa Comunicación de la Comisión, de 28 de abril de 2017, relativa al acceso a la justicia en materia medioambiental $^{15}$. Sin embargo, la propia naturaleza del instrumento elegido, una mera comunicación, "evidencia el fracaso en la realización de avances en

\footnotetext{
${ }^{14}$ a) Ser independientes, actuar sin ánimo de lucro y tener por objeto la protección del medio ambiente.

b) Disponer de una estructura que les permita alcanzar sus objetivos; estar constituidas legalmente y tener experiencia en la protección del medio ambiente.

c) Estar en posesión de declaraciones anuales de cuentas certificadas por un censor de cuentas oficial.

${ }^{15}$ Publicada en el DOUE núm. C 275, de 18 de agosto de 2017.
} 
ese tercer pilar del Convenio de Aarhus"16, dado que se trata, como la propia Comisión reconoce, de un documento de orientación que aclara cómo los particulares y las asociaciones pueden impugnar ante los órganos de las jurisdicciones nacionales las decisiones, los actos y las omisiones de las autoridades públicas vinculados a la legislación medioambiental. Del mismo modo, la Comisión pretende con esta comunicación dar orientaciones a los órganos jurisdiccionales nacionales relacionando todas las causas del TJUE sobre la materia que deben tener en cuenta cuando se enfrenten a cuestiones relacionadas con el acceso a la justicia ambiental ${ }^{17}$, algunas incluso anteriores al propio Convenio de Aarhus.

${ }^{16}$ NOGUEIRA LÓPEZ, A., "Pack Premium o pack básico. ¿Ordenamiento ambiental dual?", RADA, núm. 38, 2017, p. 318.

${ }^{17}$ En concreto, se refieren las siguientes sentencias en las que el TJUE ha tenido ocasión de pronunciarse sobre el acceso a la justicia ambiental y sus cuestiones conexas: Sentencia de 30 de mayo de 1991, Comisión/Alemania, C-361/88; Sentencia de 17 de octubre de 1991, Comisión/Alemania; Sentencia de 24 de octubre de 1996, Kraaijeveld, C-72/95; Sentencia de 14 julio de 1998, Safety Hi-Tech, C-284/95; Sentencia de 29 de abril de 1999, Standley, C-293/97; Sentencia de 7 de diciembre de 2000, Comisión/Francia, C-374/98; Sentencia de 7 de enero de 2004, Wells, C-201/02; Sentencia de 7 de septiembre de 2004, Waddenzee, C-127/02; Sentencia de 13 de marzo de 2007, Unibet, C-432/05; Sentencia de 25 de julio de 2008, Janecek, C-237/07; Sentencia de 15 de abril de 2008, Impact, C-268/06; Sentencia de 3 de julio de 2008, Comisión/Irlanda, C-215/06; Sentencia de 16 de julio de 2009, Comisión//rlanda, C-427/07; Sentencia de 30 de abril de 2009, Mellor, C-75/08; Sentencia de 15 de octubre de 2009, Djurgården, C-263/08; Sentencia de 12 de mayo de 2011, Bund für Umwelt und Naturschutz, C115/09; Sentencia de 18 octubre de 2011, Boxus, asuntos acumulados C-128/09 a C-131/09, C134/09 y C-135/09; Sentencia de 8 de marzo de 2011, LZ I, C-240/09; Sentencia de 26 de mayo de 2011, Stichting Natuur en Milieu, C-165 a C-167/09; Sentencia de 16 de febrero de 2012, Solvay y otros, C-182/10; Sentencia de 28 de febrero de 2012, Inter-Environnement Wallonie, C41/11; Sentencia de 15 de enero de 2013, Križan, C-416/10; Sentencia de 14 de marzo de 2013, Leth, C-420/11; Sentencia de 11 de abril de 2013, Edwards y Pallikaropoulos, C-260/11; Sentencia de 3 de octubre de 2013, Inuit, C-583/11P; Sentencia de 7 de noviembre de 2013, Altrip, C-72/12; Sentencia de 19 de diciembre de 2013, Fish Legal y Shirley; Sentencia de 13 de febrero de 2014, Comisión/Reino Unido, C-530/11; Sentencia de 19 de noviembre de 2014, Client Earth, C-404/13; Sentencia de 6 de octubre de 2015, East Sussex, C-71/14; Sentencia de 15 de octubre de 2015, Comisión/Alemania, C-137/14; Sentencia de 14 de enero de 2016, Grüne Liga Sachsen, C-399/14; Sentencia de 21 de julio de 2016, Comisión/Rumanía, C-104/15; Sentencia de 15 de octubre de 2015, Gruber, C-570/13; Sentencia de 28 de junio de 2016, Association France Nature Environnement, C-379/15; Sentencia de 8 de noviembre de 2016, LZ II, C-243/15; Sentencia de 10 de noviembre de 2016, Eco-Emballages, C-313/15 y C-530/15; Sentencia de 17 de noviembre de 2016, Stadt Wiener Neustadt C-348/15.

Sobre la interpretación que esta jurisprudencia comunitaria ha realizado del derecho de acceso a la justicia ambiental, véase DEL SAZ CORDERO, S., "La influencia del Convenio de Aarhus en el sistema de tutela contencioso-administrativa del Derecho alemán. Comentario a la jurisprudencia reciente del Tribunal de Justicia de la Unión Europea sobre el acceso a la justicia de las ONG ambientales. Asuntos Trianel (C-115/09) y Oso pardo (C-240/09)", RAP, núm. 188, 2012; SALAZAR ORTUÑO, E., "Implicaciones del Convenio de Aarhus en la legislación sobre acceso a la justicia de los estados: la Sentencia 'Trianel' del Tribunal de Justicia de la Unión Europea de 12 de mayo de 2011, C-115/09", RADA, núm. 23, 2012; GARCíA URETA, A., "Acceso a la justicia y costes procesales: Comentario a la Sentencia del TJUE (Sala Cuarta) de 11 de abril de 2013 (Asunto C-260/11), the Queen, a instancias de: David Edwards, Lilian Pallikaropoulos v. Environment Agency, First Secretary of State, Secretary of State for 
También esta comunicación pretende que las Administraciones nacionales puedan observar las posibles deficiencias de sus sistemas judiciales para adecuarlos a lo establecido en la profusa jurisprudencia del TJUE, a la que cita tanto en lo que se refiere al acceso a la justicia en relación con la vulneración de los derechos de información y participación como en lo referido a la posibilidad de entablar acciones judiciales frente a actuaciones $u$ omisiones de las Administraciones que sean contrarias a la legislación ambiental de la UE. Del mismo modo, se abordan los criterios de evaluación que los órganos jurisdiccionales nacionales deben emplear para evitar que los gastos procesales impidan a los ciudadanos y las ONG acceder a la justicia. En definitiva, se busca que estos sean los guardianes de la efectiva aplicación del derecho ambiental a nivel nacional, que tienen que interpretar y aplicar.

Esta comunicación de la Comisión, puro documento de orientación, como no podía ser de otro modo, excluye los litigios entre particulares en materia de medio ambiente y la revisión judicial de los actos de las instituciones de la Unión Europea.

En resumen, no se vislumbra en el horizonte comunitario ningún instrumento normativo vinculante en forma de directiva o reglamento que establezca con carácter obligatorio el reconocimiento de un acceso a la justicia en asuntos ambientales para así lograr una aplicación efectiva del Convenio de Aarhus y particularmente de su artículo 9.3.

\section{Algunos pronunciamientos recientes del TJUE}

A pesar de que, de momento, ninguna propuesta de directiva o reglamento haya salido adelante, el TJUE, como hemos visto en la profusa relación de sentencias que la citada Comunicación de la Comisión enumera, sí ha tenido ocasión de pronunciarse en más de una ocasión sobre el acceso a la justicia ambiental. En este sentido, ya la Sentencia del TJUE de 15 de octubre de 2009, que resolvía una cuestión prejudicial sobre una norma sueca y en particular sobre los requisitos de legitimación establecidos por la legislación sueca para las ONG,

Environment", REDA, 160, 2013; y EMBID IRUJO, A., "El acceso a la justicia ambiental en la jurisprudencia del Tribunal de Justicia de la Unión Europea”, RVAP, núm. 99-100, 2014. 
afirmaba que, si bien una ley nacional puede exigir que una asociación que pretende impugnar una decisión ambiental tenga un objeto social relacionado con la protección de la naturaleza y el medio ambiente, estas normas nacionales no pueden privar de alcance a las disposiciones comunitarias según las cuales quienes tienen un interés legítimo en impugnar un proyecto y quienes sean titulares del derecho menoscabado por este, entre los cuales figuran las asociaciones de protección del medio ambiente, deben poder ejercitar su acción ante los órganos jurisdiccionales competentes. Más en concreto, el TJUE señaló que la ley nacional no puede establecer un número de socios, en este caso 2.000 , requerido a un nivel tal que vaya en contra de los objetivos de la Directiva 85/337/CEE del Consejo, de 27 de junio de 1985, relativa a la evaluación de las repercusiones de determinados proyectos públicos y privados sobre el medio ambiente, y en concreto de permitir el control jurisdiccional de las operaciones a las que esta es aplicable.

Más recientemente, el TJUE lleva a cabo una amplia interpretación del artículo 9.3 del Convenio de Aarhus en la Sentencia de 20 de diciembre de 2017, en la que realiza una clara interpretación pro actione y pro defensa de la legitimación y participación de las ONG ambientales en los procesos relativos a autorizaciones de proyectos que tengan una incidencia sobre el medio ambiente, tanto para participar como parte interesada como para reconocer la posibilidad de recurso en vía administrativa o judicial a la luz del Convenio de Aarhus y del derecho ambiental de la Unión. Así, el TJUE lanza un claro mensaje de la incompatibilidad de la regulación austriaca invocada, afirmando que una ONG que opera de conformidad con las exigencias prescritas por el derecho nacional debe tener la posibilidad de impugnar ante los tribunales una decisión de autorización de un proyecto que pueda ser contrario a la obligación de prevenir el deterioro del estado de las masas de agua de acuerdo con la Directiva Marco del Agua.

Del mismo modo, el TJUE afirma que es contraria al derecho de la Unión la norma que no reconoce a las ONG ambientales el derecho a participar como partes en un procedimiento de autorización seguido en aplicación de la Directiva Marco del Agua (Directiva 2000/60/CE), y que concede el derecho de recurso contra las decisiones adoptadas al término de dicho procedimiento únicamente 
a las personas que tengan tal condición, al igual que se imponga a dichas ONG una norma procedimental nacional, de efectos preclusivos, en virtud de la cual pierdan la condición de parte en el procedimiento y no puedan, por tanto, interponer un recurso contra la decisión adoptada si no presentaron sus alegaciones en plazo durante el procedimiento administrativo y, a más tardar, en la fase oral de dicho procedimiento.

Como continúa señalando el TJUE "al negar a las organizaciones de defensa del medio ambiente el derecho de recurso contra una decisión de autorización de esa naturaleza, la normativa procedimental nacional de que se trata es contraria a las exigencias que se derivan del artículo 9, apartado 3, del Convenio de Aarhus, en relación con el artículo 47 de la Carta". Para afirmar que "corresponde al órgano jurisdiccional remitente interpretar, en la medida de lo posible, el régimen procesal de los requisitos necesarios para interponer un recurso de manera conforme tanto con los objetivos del artículo 9, apartado 3, del Convenio de Aarhus como con el objetivo de garantizar la tutela judicial efectiva de los derechos que confiere el ordenamiento jurídico de la Unión, a fin de permitir a una organización de defensa del medio ambiente como Protect impugnar ante los tribunales una decisión adoptada al término de un procedimiento administrativo que puede ser contraria al Derecho medioambiental de la Unión". En resumen, a nivel comunitario la jurisprudencia comunitaria ha ido avanzando y desarrollando el reconocimiento y la aplicación del Convenio de Aarhus pese a la ausencia de directiva o reglamento, más allá de la reciente Comunicación de la Comisión antes citada, en esta materia. Sin embargo, quizá no sea ya necesario aprobar una directiva o un reglamento teniendo en cuenta la jurisprudencia dictada por el TJUE.

\section{LA PREVISIÓN DE LA LEGISLACIÓN BÁSICA ESTATAL EN MATERIA DE ACCESO A LA JUSTICIA AMBIENTAL Y EL AMPLIO RECONOCIMIENTO DE ALGUNAS LEYES AUTONÓMICAS}

\section{Las diferentes vías judiciales de defensa de los intereses ambientales}

Con carácter previo, señalaré que en nuestro ordenamiento jurídico existen varias vías judiciales de tutela ambiental: la penal, la civil y, sobre todo, la 
contencioso-administrativa. La vía constitucional queda restringida al exclusivo recurso de amparo, mientras que en la vía comunitaria no cabe el recurso directo, si bien el procedimiento de queja ante la Comisión está dando lugar a determinados procesos contra Estados por incumplimiento de la normativa ambiental y, por otro lado, la interpretación del TJUE en materia de resolución de las cuestiones prejudiciales planteadas respecto de la legitimación ambiental es, como acabamos de ver, amplia.

En lo que respecta a la vía penal, cabe la protección ambiental a través del ejercicio de la acción por los delitos ambientales tipificados en los artículos 325 y siguientes del Código Penal. Aunque pudiera parecer una vía residual, lamentablemente son cada vez más los casos que por infracciones ambientales se están sustanciando ante la jurisdicción penal como delitos contra el medio ambiente. En este sentido, cabe recordar que, en el ámbito penal, el reconocimiento de una acción popular permite a cualquier ciudadano reaccionar contra las conductas tipificadas como delitos contra el medio ambiente, la flora y la fauna silvestres. En virtud del carácter público de la acción penal, las asociaciones constituidas para la defensa del medio ambiente también podrán ejercitar la acción penal, si bien hay también ciertas restricciones. Así lo demuestra el reciente Auto de la Audiencia Provincial de Guadalajara, de 2 de febrero de 2017, que deniega la legitimación a una ONG ambiental en consonancia con lo acordado por el Juzgado de Instrucción núm. 1 de Guadalajara, que denegó su personación al no haber lugar a esta al no cumplirse la previsión del artículo 109 bis.3 LECrim, puesto que no se acreditó que la legislación vigente le reconociera legitimación para defender los derechos de las víctimas ni que ello, en su caso, hubiera sido autorizado por las víctimas del delito.

La Audiencia confirma al Juzgado de Instrucción cuando señala lo siguiente:

Como conclusión, en nuestro ordenamiento, ha de admitirse, como regla general, la acción popular en la defensa del medio ambiente [...]. Pues bien, si los titulares de dicho derecho-deber son "todos" y no sólo los unidos con el medio ambiente por una determinada relación jurídico-material, es evidente que su defensa procesal, cuando se lesione o ponga en peligro ese derecho de disfrute, corresponde a todos los sujetos de derecho "quivis ex populo", es decir, por el solo 
hecho de tener capacidad para el ejercicio del derecho de acción o de tutela. Pues bien, sentado lo que antecede solo cabe decir que la resolución recurrida es correcta en cuanto se limita a decir que deberán cumplirse los requisitos legales para ejercitar las acciones penales, cambiando en la alzada los argumentos, apuntando a una legitimación directa como perjudicados a nivel particular por el incendio de varios socios, lo que deberá plantearse en forma en la instancia pues es obvio que resulta extemporáneo alegarlo por vez primera con ocasión del recurso además de no acreditarse ni la condición de socios ni la de perjudicados.

La vía civil es otra de las vías de acceso a la justicia ambiental a través del conocido como "derecho de inmisiones", que establece las correspondientes acciones de cesación y de responsabilidad por actividades molestas o nocivas encuadradas dentro de las conocidas relaciones de vecindad. En estos supuestos la legitimación exige un interés directo o legítimo o bien la existencia de un derecho subjetivo afectado por la actividad de que se trate, no cabiendo obviamente una acción pública de ninguna de las maneras en este orden jurisdiccional.

Como ya hemos señalado, la vía constitucional a través del recurso de amparo es otra de las posibilidades en caso de no haber obtenido satisfacción a las propias pretensiones en la justicia ordinaria. Aunque el derecho a disfrutar de un medio ambiente adecuado no se encuentra dentro de los artículos 14 a 29 de la Constitución, su relación con los derechos y libertades reconocidos en estos artículos es clara, como el derecho a la vida, la integridad física o el derecho a la inviolabilidad e intimidad del domicilio, y así ha acabado siendo admitida por el Tribunal Constitucional ${ }^{18}$.

Otra de las vías de tutela ambiental cada vez más frecuente es la del recurso ante el Tribunal Europeo de Derechos Humanos por vulneración del Convenio de Roma de 1950. A pesar de que este convenio no reconoce directamente el derecho a disfrutar de un medio ambiente adecuado, el TEDH ha ido estimando diferentes demandas interpuestas contra determinados países por vulneración de derechos reconocidos en el Convenio a causa de infracciones ambientales.

\footnotetext{
${ }^{18}$ Véase en este sentido la STC 119/2001, de 29 de mayo, en el asunto conocido como MorenoGómez relativo a la contaminación acústica, si bien no otorgó el amparo por falta de prueba en la existencia de los daños alegados imputables a la inactividad de la Administración. Sobre este mismo asunto, posteriormente el TEDH, en sentencia de 16 de noviembre de 2004, condenó al Reino de España por vulneración del derecho a la intimidad e inviolabilidad del domicilio.
} 
Es el caso de la Sentencia López-Ostra y de la Sentencia Moreno-Gómez, por las que se condenó al Reino de España a través del conocido "efecto reflejo" por vulneración de derechos causados por actividades perjudiciales para el medio ambiente, o de la más reciente Cuenca-Zarzoso c. España, de 16 de enero de 2018, también relacionada con inmisiones acústicas toleradas inexplicablemente por la Administración local.

En el ámbito de la justicia comunitaria, dicha vía judicial está vedada a los particulares, quedando, eso sí, la posibilidad de queja ante la Comisión en caso de que un Estado vulnere la normativa ambiental comunitaria para que esta, si lo estima oportuno, plantee la correspondiente acción ante el Tribunal de Luxemburgo por incumplimiento de Estado.

La vía de recurso a la que se refiere la LIPPJMA y a la que, por tanto, nos vamos a referir principalmente es la vía de recurso administrativo y la ulterior vía judicial contencioso-administrativa, la más habitual en cuestiones ambientales. Si el artículo 45.2 establece como obligación de los poderes públicos el velar por la utilización racional de los recursos naturales, esto supone una clara vinculación al poder ejecutivo y su administración respectiva, que son finalmente los que deben lograr que la profusa normativa ambiental se cumpla por sus destinatarios. En unos casos, sometiendo determinadas actividades a autorización; en otros, inspeccionando y, en su caso, sancionando. Pues bien, ante actos, resoluciones, reglamentos, planes o inactividad es donde surge principalmente la posible impugnación.

\section{Previsiones de la LIPPJMA en orden a la legitimación condicionada}

En primer término, la cuestión del acceso a la justicia ambiental ya sea vía recurso administrativo o recurso judicial radica en una cuestión de legitimación. Es decir, depende de que quien recurre un acto de la Administración o denuncia determinadas actuaciones ambientales tenga un interés legítimo o un interés directo o pueda ver alguno de sus derechos subjetivos afectados por una determinada decisión de contenido ambiental. De no ser así, cabría apelar al reconocimiento de un interés difuso, colectivo y general que es el medio 
ambiente lo que debiera conducir a reconocimiento para ello de una acción pública.

La LIPPJMA estableció una regulación del acceso a la justicia ambiental, a mi juicio, suficiente en cuanto a la legitimación, y en ello convenimos con MARTíN MATEO, para quien la fórmula de la LIPPJMA es la más satisfactoria, reconociéndose la legitimación procesal ambiental o ecológica solo a grupos creados para la defensa de intereses de esta índole, a los que expresamente se reconoce esta aptitud por la Administración, ya que no es misión de los ciudadanos aislados procurar el correcto funcionamiento del Estado de Derecho $^{19}$. Otros autores, como LOPERENA, señalan que la eficacia de los derechos e intereses colectivos ambientales exige que la tutela judicial se abra sin restricciones ${ }^{20}$, siendo preferible introducir una acción pública general de manera que cualquier ciudadano, cualquier persona jurídica, sin necesidad de tener que acreditar un interés legítimo o un derecho subjetivo, pudiera impetrar la tutela de los jueces y tribunales por una presunta vulneración de las normas ambientales, tal y como se prevé en materia de derecho urbanístico y en materia de $\operatorname{costas}^{21}$.

No obstante, nuestra legislación procesal y la acción pública condicionada prevista en la LIPPJMA dan satisfacción, en lo que al acceso a la justicia ambiental se refiere, desde el punto de vista de la legitimación. No olvidemos que la amplia interpretación de la jurisprudencia del artículo 19.1 de la Ley 29/1998, de 13 de julio, reguladora de la Jurisdicción Contencioso-administrativa (de ahora en adelante, LJCA), basada en el principio pro actione, además de la propia regulación de la LIPPJMA, ha posibilitado en todo momento que quien

\footnotetext{
${ }^{19}$ Cfr. MARTÍN MATEO, R., "La problemática del accionariado popular", Revista de Estudios de la Vida Local, núm. 179, 1973, p. 477.

${ }^{20}$ LOPERENA ROTA, D., Los principios del derecho ambiental, IVAP-Civitas, Madrid, 1998, p. 70.

${ }^{21}$ Cabe destacar JORDANO FRAGA, J., La protección del derecho a un medio ambiente adecuado, Bosch, Barcelona, 1995, p. 455. Según este autor, la acción popular en materia ambiental es un mínimo inicial constitucional exigible al legislador, de tal suerte que, a su juicio, la Constitución exige que en los contenciosos ambientales exista, al menos, una acción popular que permita combatir e impugnar las decisiones de la Administración. En este mismo sentido, la enmienda núm. 33 del Grupo Parlamentario Mixto y la núm. 102 de IU-ICV (BOCG, núm. 68-4, de 3 de marzo de 2006), en la discusión de la LIPPJMA en sede parlamentaria, solicitaban la acción pública de manera que cualquier ciudadano pudiera exigir a los órganos administrativos y ante los tribunales contencioso-administrativos la observancia de las disposiciones ambientales.
} 
sea titular de un derecho subjetivo o interés legítimo haya podido actuar, y que también lo hayan podido hacer las ONG ambientales cuando han querido. Y es que no debemos dejarnos llevar por idealismos alejados de la realidad, el medio ambiente no tiene quien lo defienda y defenderlo cuesta tiempo y dinero, por lo que nadie que no sea titular de la legitimación exigida estará dispuesto a entablar una acción judicial en defensa del medio ambiente sin más, dado lo que ello conlleva.

Igualmente, la LIPPJMA limita el objeto del recurso restringiéndolo a los actos u omisiones de las autoridades públicas, frente a la previsión del Convenio, que lo extiende también a los actos $u$ omisiones de los particulares, no pudiendo, por tanto, ser demandadas las personas privadas que asuman responsabilidades, presten servicios o ejerzan funciones públicas relacionadas con el medio ambiente, salvo que el recurrente ostente un interés legítimo.

Lo cierto es que, como se ve, no se trata de una acción pública, ni mucho menos. Estamos ante una acción pública peculiar limitada a determinados sujetos que, además, deben cumplir una serie de requisitos cuya acreditación ha de ser exacta y clara para poder acceder a la justicia ambiental. A juicio de PEÑALVER I CABRÉ, el recurso previsto en el artículo 9.3 del Convenio de Aarhus ha sido muy mal adaptado tanto por la UE como por la LIPPJMA porque se ha limitado a habilitar a determinadas ONG ambientales para recurrir actos $u$ omisiones de las autoridades públicas contrarias a la legislación ambiental22.

El Documento de trabajo de la Comisión sobre la revisión de la aplicación del Derecho ambiental en España ${ }^{23}$ señala que, si bien el sistema jurídico español garantiza a los ciudadanos la posibilidad de llevar asuntos medioambientales a los tribunales, en los casos de omisión e inacción por parte de la Administración, los ciudadanos encuentran dificultades a la hora de disponer de capacidad procesal para impugnar la situación.

a) Los requisitos de legitimación exigidos a las ONG

22 PEÑALVER I CABRÉ, "El derecho..." cit., p. 2349.

${ }^{23}$ SWD (2017) 42 final, 03.02.2017. 
La LIPPJMA establece una especie de acción pública a favor de las ONG condicionada al cumplimiento de una serie de requisitos. La acción prevista opera en el doble ámbito administrativo y jurisdiccional, bien a través de los procedimientos de recursos administrativos establecidos en la Ley 39/2015, bien mediante el recurso contencioso-administrativo previsto en la Ley 29/1998.

En concreto, su artículo 22 señala que "los actos y, en su caso, las omisiones imputables a las autoridades públicas que vulneren las normas relacionadas con el medio ambiente enumeradas en el artículo 18.1 podrán ser recurridas por cualesquiera personas jurídicas sin ánimo de lucro", a las que el artículo 23, párrafo primero, les exige una serie de requisitos: tener entre los fines acreditados en sus estatutos la protección del medio ambiente en general o la de alguno de sus elementos en particular; estar constituidas legalmente al menos dos años antes del ejercicio de la acción y que vengan ejerciendo de modo activo las actividades necesarias para alcanzar los fines previstos en sus estatutos; y, por último, que, según sus estatutos, desarrollen su actividad en un ámbito territorial que resulte afectado por la actuación o, en su caso, omisión administrativa. En la discusión de estos preceptos, algunas iniciativas parlamentarias plantearon requisitos adicionales para la legitimación de estas personas jurídicas, tales como "estar debidamente registrada y al corriente de sus obligaciones con Hacienda y la Seguridad Social”, con lo que se trataba de limitar al máximo posibles abusos al amparo de esta ley, o "que el objeto de la actividad de la entidad interesada guardase una relación clara y directa con el plan, programa o disposición general". Ambas iniciativas ${ }^{24}$, claramente restrictivas del acceso a la justicia, fueron rechazadas ${ }^{25}$; otras, en cambio, abogaban por el reconocimiento de una acción pública ambiental sin restricción alguna ${ }^{26}$.

Ejemplo del lógico rigor que debe exigirse en la acreditación de los requisitos establecidos son algunos pronunciamientos jurisprudenciales recientes. Es el

\footnotetext{
${ }^{24}$ Enmiendas núm. 80 y núm. 81 del Grupo Parlamentario Popular (DOCG, núm. 68-4, de 3 de marzo de 2006).

${ }^{25}$ Nada que ver con las limitaciones de alguna legislación comunitaria como la sueca, que exige al menos 2.000 miembros y que ha dado lugar al planteamiento de una cuestión prejudicial resuelta por el TJCE en la Sentencia de 15 de octubre de 2009 a la que ya hemos hecho referencia supra.

${ }^{26}$ Enmiendas núm. 33 del Grupo Parlamentario Mixto y núm. 102 de IU-ICV (BOCG, núm. 68-4, de 3 de marzo de 2006).
} 
caso de la STSJ Castilla y León, de 27 de noviembre de 2017, que deniega la legitimación de una asociación recurrente sobre la base de los siguientes argumentos:

Y en este caso, según consta en el art. 1 de los Estatutos de la Asociación recurrente, AGERDCYL se constituye en Valladolid el día 15 de febrero de 2013, por lo que es claro que desde esa fecha -incluso habría de estarse a la fecha de su inscripción en el registro de asociaciones, como resulta de la STS de 29 de abril de 2016 - no había transcurrido el plazo de "dos años", previsto en el citado art. 23.1.b) de la Ley 27/2006, cuando se interpuso el 4 de julio de 2014 el recurso de alzada contra la citada Resolución de 14 de abril de 2014.

De la misma manera, la STS de 29 de abril de 2016 inadmite el recurso interpuesto por una ONG ambiental contra el otorgamiento de un permiso de investigación de hidrocarburos a una empresa mercantil por no cumplir el requisito de dos años de antigüedad exigido en el artículo 23.1.b LIPPJMA:

[...] la asociación recurrente podría ostentar legitimación activa en asuntos de protección del medio ambiente, pero no observa el requisito temporal contemplado en el artículo 23.1.b) de la Ley 27/2006 que expresamente exigen el transcurso de dos años desde la constitución de la Asociación, siendo esta la legislación nacional a la que se remite el artículo 9 del Convenio de Aarhus.

Por otro lado, el dato de que el Consejo de Ministros haya tramitado el recurso de reposición deducido por la Asociación Desarrollo Verde no resulta determinante para el reconocimiento de la legitimación, pues, en este caso, la fecha relevante para el reconocimiento de la legitimación de la Asociación es cuando se produce su inscripción en el registro, al así indicarlo el artículo 10.2 de la Ley Orgánica $1 / 2002$, que dispone "la inscripción registral hace pública la constitución y los Estatutos de las asociaciones y es garantía, tanto para los terceros que con ellas se relacionan, como para sus propios miembros".

Y en este caso la Asociación aquí recurrente no ha acreditado $-\mathrm{y}$ a ella le correspondía - el cumplimiento del requisito previsto en el mencionado art. 23.1.b) de la Ley $27 / 2006$ que, por otra parte, no se alega por ella.

En el mismo sentido negativo se pronuncia la STSJ de la Comunidad Valenciana, de 18 de diciembre de 2017, en relación con el recurso planteado por una entidad mercantil contra la modificación de una autorización ambiental integrada de una 
planta de tratamiento de residuos urbanos y vertedero de residuos no peligrosos, en este caso por no tratarse de una ONG:

La sociedad actora, pese a la alegación de estos preceptos, y el pleno conocimiento de esta oposición formulada por la administración, como se desprende de su escrito de conclusiones, no ha acreditado que sea una persona jurídica sin ánimo de lucro; ni tampoco que, su objeto social, sea cualquiera de los tres que menciona el artículo 23 de la Ley 27/2006, y en consecuencia carece de legitimación para el ejercicio de la acción pública.

b) La restricción de las materias ambientales sobre las que puede versar la acción pública

Existe otro límite respecto al objeto del proceso ambiental establecido por la LIPPJMA: el de las actuaciones relacionadas o amparadas en las disposiciones que el artículo 18 LIPPJMA enumera. En este sentido, el Convenio de Aarhus se refiere a todas las disposiciones de derecho medioambiental. Ahora bien, de una lectura del listado previsto en el artículo 18 LIPPJMA cabe plantearse si el recurso, tal y como se configura en el Convenio de Aarhus, puede ser utilizado en nuestro ordenamiento interno. La Sentencia del Tribunal Supremo de 16 de junio de 2016 lo pone de manifiesto al negar la condición de interesada en vía administrativa a una asociación para solicitar la caducidad de unas concesiones mineras, puesto que entiende que la asociación no actuaba para la defensa de la legalidad ambiental al alegar solo incumplimientos de la normativa minera y no de la medioambiental a la que se refiere el artículo 18 LIPPJMA. Así, la Sentencia señala:

[...] para proclamar la legitimación, el interés de la Asociación Plataforma Oro No, en la declaración de caducidad de concesiones mineras, que es lo que niega la Administración, es necesario atender a si con esta solicitud se estaba impugnando una omisión de la autoridad administrativa que pudiera afectar a algunos de los sectores concernidos por el art. 18 de la Ley 27/2006. Y para ello hay que estar a los motivos por los que se solicitó la caducidad de las concesiones mineras. La lectura del escrito de solicitud de caducidad permite comprobar que ninguno de los motivos invocados trasciende del puro interés de legalidad, y ninguno tiene trascendencia ni directa ni indirecta, para la protección del medio ambiente. [...] La lectura del escrito de solicitud permite constatar que no hay ninguna actuación 
u omisión de la Administración, que aun de ser ciertos los hechos que en su escrito alega la Asociación Plataforma Oro No, pudiera comprometer directa o indirectamente el medio ambiente en ninguno de los ámbitos enunciados en el art. 18 de la Ley 27/2006. Por ello se constata que, con independencia del fin último o utilidad remota que inspira los Estatutos de la Asociación, de oponerse a este tipo de actividad minera en el entorno de Tapia de Casariego, lo cierto es que en su solicitud tan sólo existe un fin de control de legalidad, pero este finalidad no encuentra cobertura en la acción pública que regula el art. 23 , en relación con los art. 22 y 18 de la Ley 27/2006, que la sentencia de instancia ha aplicado indebidamente. En consecuencia, el motivo de casación debe prosperar, y procede casar y anular la sentencia de instancia.

El ámbito de toda acción ambiental debiera ser el "medio ambiente" en sentido amplio, algo que, por obvio, huelga decirlo. No obstante, la LIPPJMA, en su artículo 22, otorga legitimación activa a las citadas personas jurídicas para poder recurrir o impugnar cualquier acto u omisión de las Administraciones públicas de contenido ambiental, entendiendo por tal contenido ambiental las que cita en su artículo 18.1, que son: a) protección de las aguas; b) protección contra el ruido; c) protección de los suelos; d) contaminación atmosférica; e) ordenación del territorio rural y urbano y utilización de los suelos; f) conservación de la naturaleza, diversidad biológica; g) montes y aprovechamientos forestales; $h$ ) gestión de los residuos; i) productos químicos, incluidos los biocidas y los plaguicidas; j) biotecnología; k) otras emisiones, vertidos y liberación de sustancias en el medio ambiente; l) evaluación de impacto ambiental; y m) acceso a la información, participación en la toma de decisiones y acceso a la justicia en materia de medio ambiente.

Como se ve, prácticamente todas las cuestiones relacionadas con el medio ambiente, junto, eso sí, a las exclusiones habituales en materia de defensa nacional, seguridad pública, protección civil en casos de emergencia y salvamento de la vida humana en el mar.

No era necesario, a mi juicio, remitir a un artículo en el que se prevé o se cita un listado exhaustivo de materias de contenido ambiental, dado que se corre el riesgo de que, si alguna de esas materias no se incluye en alguna ley de contenido ambiental, la acción pública quede fuera porque de su enunciación expresa parece que la intención del legislador es establecer un numerus clausus. 
Hubiese bastado con hacer una referencia genérica a la infracción de las normas de contenido ambiental, con las tradicionales exclusiones para esta limitada acción pública que la LIPPJMA reconoce, puesto que, de lo contrario, pueden quedar fuera materias como la contaminación electromagnética, que no se cita.

\section{c) Sobre el ámbito territorial de actuación}

Otra de las cuestiones que sigue planteando algún problema es la relativa al requisito del ámbito territorial de la ONG que ejerce la acción. Un requisito absurdo teniendo en cuenta que las más importantes tienen un ámbito nacional o internacional. No obstante, el caso se plantea una vez más en la reciente STSJ del Principado de Asturias, de 24 de julio de 2017, que estima el recurso planteado contra las emisiones de una central térmica. En este caso, el TSJ señala lo siguiente:

Como primera cuestión y antes de examinar los motivos aducidos en la interposición del recurso, tenemos que resolver la supuesta falta de legitimación invocada por el Ayuntamiento de Ribera de Arriba respecto a la asociación recurrente.

Se plantea dicha alegación como una causa de inadmisión del recurso prevista en el artículo 69.b) de la Ley Reguladora de esta Jurisdicción, por estimar que no cumple las condiciones legales establecidas por la Ley 27/2006, de 18 de julio, por la que se regulan los derechos de acceso a la información, de participación pública y de acceso a la justicia en materia de medio ambiente, toda vez que no se cumple con lo dispuesto en el artículo 23.1.c) de dicha Ley, al radicar la sede social de la asociación y desarrollar su actividad en Madrid, ámbito territorial diferente al que afecta la resolución recurrida.

La citada Ley incorpora la acción popular en asuntos medioambientales, señalando el artículo 22 que los actos y, en su caso, las omisiones imputables a las autoridades públicas que vulneren las normas relacionadas con el medio ambiente enumeradas en el artículo 18.1, podrán ser recurridas por cualesquiera personas jurídicas sin ánimo de lucro que reúnan los requisitos establecidos en el artículo 23, a través de los recursos administrativos, así como a través del recurso contencioso administrativo [...]. Figurando en los estatutos de la Asociación recurrente que sus objetivos principales son contribuir a la protección del medio ambiente a través del estudio, aplicación y desarrollo del Derecho Internacional y 
fomentar la concienciación de la sociedad sobre las responsabilidades derivadas de la degradación ambiental, desarrollando sus funciones en la totalidad del Estado español, sin perjuicio de que pueda realizarlas en el extranjero, entendemos que cumple los requisitos establecidos en los preceptos anteriormente citados, sin que se pueda delimitar su ámbito de actuación al del territorio en el que tiene su sede social.

Un requisito, como se ve, que se elude fácilmente con una previsión estatutaria nacional o europea en los respectivos estatutos de cualquier ONG ambiental porque, además, debemos recordar que la contaminación no conoce fronteras y, dado que es un interés difuso o colectivo, en nada debiera tenerse en cuenta la limitación territorial dentro del territorio nacional para poder ejercer la acción pública peculiar que la LIPPJMA prevé.

\section{d) Una preocupante previsión quizá más restrictiva en evaluación ambiental}

A los requisitos señalados en la LIPPJMA parece haberse sumado alguno más en materia de EIA y EAE por mor de la previsión del artículo 5 de la Ley 21/2013, de 9 de diciembre, de evaluación ambiental (LEA), que, al definir las personas de conformidad con la LIPPJMA, matiza el primer requisito, señalando lo siguiente: “i) Que tengan, entre los fines acreditados en sus estatutos la protección del medio ambiente en general o la de alguno de sus elementos en particular, y que tales fines puedan resultar afectados por la evaluación ambiental". BERBEROFF se pregunta si con esta previsión se está restringiendo la legitimación para recurrir de las asociaciones de protección del medio ambiente ${ }^{27}$, pero debemos entender que no, dado que supondría una modificación expresa de la LIPPJMA que la LEA no refiere y, sobre todo, porque limitaría tremendamente la posibilidad de recurso y podría llevar al absurdo de inadmitir un recurso si el objeto ambiental no está relacionado con la especialidad o sector ambiental de la concreta ONG. Así, una ONG ambiental ornitológica solo podría ejercer la acción contra proyectos que, además de incidir sobre el medio ambiente en su conjunto, tuvieran una especial incidencia sobre la

\footnotetext{
${ }^{27}$ BERBEROFF, D., "La tutela judicial 'ambiental' efectiva a la luz de la Ley 21/2013, de 9 de diciembre, de evaluación ambiental", Revista Urbanismo, 1 de marzo de 2014.
} 
avifauna y no los demás, lo que a mi juicio conduciría a una restricción injustificada.

\section{e) La reciente jurisprudencia del Tribunal Supremo}

Como ya se ha venido señalando, la jurisprudencia viene reconociendo la legitimación de las ONG ambientales en un sentido amplio, salvo claro incumplimiento de los requisitos legalmente establecidos $\mathrm{y}$, por otro lado, el propio artículo 19.1 LJCA también lo ha permitido.

Tras la entrada en vigor de la LIPPJMA, ya varias sentencias del Tribunal Supremo, como las SSTS 25 de junio de 2008, 1 de diciembre de 2009, 25 de mayo de 2010, 7 de junio de 2013 o 21 de diciembre de 2016, entre otras, habían venido resolviendo cuestiones de estricta legitimación y de aplicación de la LIPPJMA en un sentido amplio.

Pero en orden a la legitimación ambiental incluso dentro de un procedimiento administrativo sancionador, su reconocimiento y su amplia interpretación, me permito citar, por todas, la reciente STS de 7 de julio de 2017, que resuelve el recurso de casación interpuesto por la Fundación Oceana contra la STSJ de Madrid, de 18 de marzo de 2015, que había desestimado su recurso contra la resolución del Ministerio de Fomento, de 15 de noviembre de 2012, que inadmitió el recurso de alzada promovido contra la resolución de la Dirección General de la Marina Mercante, de 7 de marzo de 2012, que negó legitimación a la recurrente para ser parte en el procedimiento sancionador promovido contra los buques Burgas 3 y Schasckengborg por infracción consistente en vertidos contaminantes.

La Sentencia del Tribunal Supremo, haciendo un extraordinario resumen de su propia jurisprudencia en la cuestión antes citada, realiza una interpretación acorde con el acceso a la justicia ambiental y estima el recurso, casando la sentencia de instancia y reconociendo la legitimación de la Fundación recurrente. De esta forma, señala:

Independientemente de la acción popular en materia medioambiental, prevista en el artículo 22 de la Ley 27/2006, las citadas SSTS de 25 de junio de 2008 y de 25 de mayo de 2010, que se hace eco de la primera, declaraban, como antes quedó 
recogido en el fundamento de derecho cuarto, apartado $B$, al reseñar aquellas sentencias, la especial y decidida protección del medio ambiente por parte del artículo 45 de la Constitución Española, y el carácter amplio, difuso y colectivo de los intereses y beneficios que con su protección se reportan a la misma sociedad —como utilidad substancial para la misma en su conjunto-, que obliga a configurar un ámbito de legitimación en esta materia, en el que las asociaciones como la recurrente deben considerarse como investidas de un especial interés legítimo colectivo, lo que conduce a entender que las mismas, con la impugnación de decisiones medioambientales como las de autos, no están ejerciendo exclusivamente una defensa de la legalidad vigente, sino que están actuando en defensa de unos intereses colectivos que quedan afectados por el carácter positivo o negativo de la decisión administrativa que se impugna. La especial significación constitucional del medio ambiente amplía, sin duda, el marco de legitimación de las asociaciones como la recurrente, las cuales no actúan movidas exclusivamente por la defensa de la legalidad sino por la defensa de unos cualificados o específicos intereses que repercuten en la misma, y, con ella, en toda la sociedad a quien también el precepto constitucional le impone la obligación de la conservación de los mismos. La sentencia recurrida no tiene en cuenta esta línea jurisprudencial. [...] De esta manera, la Fundación Oceana ostenta un interés legítimo teniendo en cuenta la significación constitucional del medio ambiente $y$ el que se ha dado en denominar principio de efectividad del Derecho Ambiental $y$, por ello, al personarse en el procedimiento sancionador no actuó movida, exclusivamente, por la defensa de la legalidad sino por la defensa del medio ambiente marino y los intereses que tiene en que el medio marino sea protegido eficazmente. La sentencia recurrida niega que la recurrente ostente intereses legítimos en virtud de lo previsto en el artículo 45 de la Constitución. Sin embargo, el resultado del procedimiento sancionador iniciado por el vertido de hidrocarburos al medio marino también afecta a la esfera jurídica de la Fundación Oceana.

Para afirmar más adelante:

[...] la Ley 27/2006 no limita el denominado "derecho de acceso a la justicia en materia ambiental" a supuestos de vulneración de lo dispuesto en esa Ley en materia de información y participación pública pues su artículo 22 prevé la acción popular en asuntos medioambientales, permitiendo el ejercicio del derecho de acceso a la justicia en materia ambiental con la 
posibilidad de impugnar administrativa y jurisdiccionalmente la actividad de la administración que vulnere la normativa medioambiental, el cual es un reflejo de lo previsto en el artículo 9.3 del Convenio de Aarhus [...]. Y, en base a lo previsto en su artículo 9.3 la Fundación Oceana estaba legitimada para impugnar la actividad de la administración puesto que el objeto de dicha impugnación era un procedimiento abierto por una infracción cometida a una disposición de derecho ambiental por unos buques que causaron una serie de daños al medio marino.

Esta reciente sentencia aquí citada resume a las claras la amplia interpretación que de la denominada acción pública ambiental debe realizarse por los jueces y tribunales del orden contencioso-administrativo no ya solo cuando lo que se impugne sea la vulneración de los derechos de información y participación previstos en la propia LIPPJMA, sino también cuando lo que se impugne o se recurra sean acciones $u$ omisiones de la Administración en relación con el cumplimiento o incumplimiento de la profusa legislación medioambiental.

\section{Las previsiones de la legislación autonómica en cuanto al acceso a la} justicia ambiental: heterogeneidad y dudosa constitucionalidad no resuelta por la STC $151 / 2012$

Hemos visto como la jurisprudencia interpreta ampliamente la legitimación reconocida tanto en el artículo 19 LJCA como en el artículo 23 LIPPJMA, salvo en el que caso de que no se cumplan claramente los requisitos establecidos para la denominada "acción pública ambiental".

Ahora bien, desde hace muchos años se ha producido un fenómeno curioso en el ámbito de la legislación autonómica ambiental que ha previsto tal legitimación, puesto que esta va más allá que la legislación básica ambiental y que la propia legislación procesal sobre la que el Estado tiene competencia exclusiva.

Muchas leyes autonómicas incluyen la denominada acción pública ambiental en clara contravención al $149.1 .6^{\circ} \mathrm{CE}$ e ignorando los requisitos de legitimación que establece la LIPPJMA.

Esta duda respecto de la constitucionalidad de tales previsiones autonómicas que reconocen una acción pública ambiental pudo dirimirla el Tribunal 
Constitucional, pero, so pretexto de falta de objeto del proceso, no lo hizo en la STC 151/2012, que resolvió la cuestión de inconstitucionalidad de la Ley 3/1998, de 27 de febrero, General de Protección del Medio Ambiente del País Vasco, cuyo artículo 3.4 reconoce la acción pública para exigir el cumplimiento de lo previsto en ella tanto en la vía administrativa como en la jurisdiccional. En concreto, la Sala de lo Contencioso-Administrativo del Tribunal Superior de Justicia del País Vasco, mediante Auto de 4 de noviembre de 2011, acordó elevar cuestión de inconstitucionalidad sobre el citado artículo ante su posible contradicción con el artículo 149.1.6 $\mathrm{CE}$, conforme al cual corresponde al Estado la competencia exclusiva sobre "legislación procesal, sin perjuicio de las necesarias especialidades que en este orden se deriven de las particularidades del derecho sustantivo de las Comunidades Autónomas", dado que el artículo 22 LIPPJMA limita la legitimación para el ejercicio de la acción pública en materia medioambiental a las personas jurídicas sin ánimo de lucro que reúnan los requisitos enunciados en el artículo 23 , habiéndose dictado ambos preceptos (arts. 22 y 23) en ejercicio de la competencia estatal ex artículo $149.1 .6^{\circ} \mathrm{CE}$, tal y como se indica en la disposición final tercera de la Ley $27 / 2006^{28}$. Fue esta una oportunidad perdida en la que el Tribunal Constitucional se podía haber pronunciado a las claras en pos de una mayor seguridad jurídica frente al confuso panorama articulado por la legislación autonómica en materia de legitimación ambiental que a continuación describo. Curiosamente, no ha vuelto a plantearse tal cuestión, cuando no son pocos los ejemplos de la legislación autonómica que plantean la misma duda por sus previsiones en este orden que, a modo de evidencia, citamos a continuación.

$Y$ es que algunas leyes autonómicas reconocen la acción pública en vía administrativa, otras en vía administrativa y judicial, y otras simplemente se

\footnotetext{
${ }^{28}$ La Abogacía del Estado solicitaba la estimación de la cuestión al considerar que "la acción pública o popular ante los tribunales contencioso-administrativos es una institución procesal [...] que se caracteriza precisamente por suponer una excepción a la regla general de legitimación [derecho o interés legítimo, art. 19.1 a) LJCA]. No existiendo particularidad del derecho sustantivo vasco que haga necesaria la acción popular como especialidad procesal [...] el legislador vasco era radicalmente incompetente para establecer la acción pública 'para exigir el cumplimiento de lo dispuesto' en la ley autonómica de protección ambiental. Y esta radical incompetencia es independiente de, e indiferente a, la mayor o menor coincidencia con una hipotética norma procesal estatal, pues justamente la doctrina constitucional de las leges repetitae (por todas, SSTC 47/2004, de 25 de marzo, FJ 8, y 341/2005, de 21 de diciembre, FJ 9) se alza contra este tipo de invasiones competenciales de los legisladores autonómicos".
} 
remiten a la legislación estatal y a la LIPPJMA, adoptando una posición más prudente. Veamos varios ejemplos, algunos muy recientes, otros no tanto, anteriores incluso a la LIPPJMA y aún vigentes.

Entre las disposiciones autonómicas que reconocen una total legitimación, cabe destacar la Ley 4/2007, de 8 de marzo, de Evaluación Ambiental en Castilla-La Mancha. Como su propia exposición de motivos señala, recoge una novedosa determinación, inexistente en la vigente Ley $5 / 1999$, de 8 de abril, sobre el ejercicio de la acción pública orientada a posibilitar la exigencia del cumplimiento de las disposiciones de la ley o de sus normas de desarrollo ante los órganos administrativos o judiciales. Así, en su artículo 53, bajo la rúbrica de acción pública, establece lo siguiente: "Las personas interesadas, a los efectos de esta ley, podrán exigir ante los órganos administrativos $y$, de acuerdo con la legislación estatal, ante los tribunales la observancia de lo establecido en esta ley y en las disposiciones que se dicten en su desarrollo y aplicación".

Otro ejemplo es el Decreto Legislativo 1/2009, de 21 de julio, por el que se aprueba el texto refundido de la Ley reguladora de los residuos, de Cataluña, cuyo artículo 106.1 establece que es pública la acción para exigir ante los órganos administrativos y los tribunales del orden jurisdiccional correspondiente la observancia de todo lo que dispone esta ley. Algo que curiosamente no se prevé en otras leyes ambientales sectoriales de Cataluña, como es el caso de la Ley $20 / 2009$, de 4 de diciembre, de prevención y control ambiental de las actividades, que regula las técnicas de intervención de actividades con incidencia ambiental, sea el caso, por ejemplo, de actividades de gestión de residuos.

En el mismo sentido, la Ley 6/2014, de 25 de julio, de Prevención, Calidad y Control ambiental de Actividades en la Comunitat Valenciana, señala en su artículo 103.1 que "será pública la acción para exigir ante los órganos administrativos y los tribunales la observancia de lo establecido en esta ley y en las disposiciones que se dicten en su desarrollo y aplicación". Otra disposición más reciente es la Ley 12/2016, de 17 de agosto, de evaluación ambiental de las Illes Balears, cuyo artículo 4.6 señala esto: "De acuerdo con la legislación aplicable, es pública la acción para exigir ante los órganos administrativos y los tribunales de la jurisdicción contenciosa el cumplimiento de lo que dispone esta 
ley". Aspecto sobre el que curiosamente no entra la STC 109/2017, que resolvió el recurso de inconstitucionalidad contra esta ley y anuló algunos de sus preceptos.

Otras CC. AA., quizá siendo conscientes de la problemática competencial, se remiten en su legislación más reciente a lo previsto en la legislación estatal. Es el caso de la Ley 4/2017, de 13 de julio, del Suelo y de los Espacios Naturales Protegidos de Canarias, cuyo artículo 327.5 dispone lo siguiente: "La acción popular en asuntos medioambientales se regirá, en todo caso, por lo dispuesto en la legislación estatal aplicable"; o también el de la Región de Murcia, donde la actual Ley 4/2009, de 14 de mayo, de Protección Ambiental Integrada, rectifica la Ley 1/1995, de 8 de marzo, de Protección del Medio Ambiente de la Región de Murcia, que reconocía la acción pública para exigir ante los órganos administrativos y judiciales la observancia de lo establecido en ella; así, el artículo 6 de la nueva ley se limita a señalar esto: "Los derechos de acceso a la información y participación pública en los asuntos de carácter ambiental, así como la acción popular en asuntos medioambientales, se ejercerán de acuerdo con lo establecido en la Ley $27 / 2006 "$.

Por su parte, el Decreto Legislativo 1/2015, de 12 de noviembre, por el que se aprueba el texto refundido de la Ley de Prevención Ambiental de Castilla y León, en su artículo 88 señala que será pública la acción para denunciar las infracciones administrativas previstas en esta ley, expresión equívoca, ya que la potestad de denunciar cualquier infracción de una ley, cualquiera que sea, es un derecho de todo ciudadano e incluso un deber. Cosa distinta es que, además de ello, el denunciante pueda personarse en el correspondiente procedimiento sancionador como interesado e incluso recurrir la resolución administrativa sancionadora que se dicte si entiende que no es ajustada a derecho. Como señala GARCÍA URETA, los ciudadanos no tienen derecho a castigar a otros por medio de un procedimiento administrativo sancionador, ya que el ejercicio de esta potestad queda reservado a la Administración, si bien "en cuanto víctima posible del ilícito administrativo, aquél tiene un claro interés en solicitar el ejercicio del poder público punitivo y en participar en el procedimiento previsto, pudiendo asimismo, acudir a 'otros tipos de medidas sancionadoras que pueden 
reportar beneficios claros y directos a los particulares'” ${ }^{29}$. La jurisprudencia mantiene el criterio de negar legitimación en los procedimientos sancionadores, a excepción de aquellos en que se reconoce la acción popular al denunciante en quien no concurra el carácter de perjudicado o que sea titular de un interés representado por la obtención de una ventaja o utilidad mediante el ejercicio de la acción ${ }^{30}$, debiendo rechazarse la legitimación cuando motivadamente se aprecie mala fe o abuso de derecho en el denunciante. En todo caso, es claro que el Convenio de Aarhus no piensa en la presentación de denuncias, sino en acciones administrativas y judiciales efectivas contra acciones $u$ omisiones de las autoridades públicas o los particulares, si bien la reciente STS de 7 de julio de 2017 citada anteriormente de manera destacada sí reconoce tal legitimación en un procedimiento sancionador al amparo de la LIPPJMA, como hemos visto.

En otros casos, el legislador autonómico no cita la acción en sede judicial, limitándose a reconocer tal acción pública circunscrita exclusivamente al ámbito del recurso administrativo. La disposición adicional primera de la Ley 16/1995, de 4 de mayo, Forestal y de Protección de la Naturaleza de la Comunidad de Madrid, señala que "será pública la acción de exigir ante los órganos administrativos competentes la observancia de lo establecido en esta Ley y en las normas que puedan dictarse para su desarrollo y aplicación". Similar es la previsión del Decreto Legislativo 1/2015, de 29 de julio, del Gobierno de Aragón, por el que se aprueba el texto refundido de la Ley de Espacios Protegidos de Aragón, cuyo artículo 6 establece lo siguiente: "Será pública la acción para exigir de las Administraciones Públicas el cumplimiento de esta ley y demás disposiciones que la desarrollen", como se ve, circunscrita al ámbito de exigencia ante las Administraciones públicas. De igual modo, la Ley 8/2003, de 28 de octubre, de la Flora y la Fauna Silvestres, de Andalucía, en su artículo 68.2 dispone: "Será pública la acción para exigir ante las Administraciones públicas la observancia de lo establecido en la presente Ley y disposiciones de desarrollo y aplicación”. Idénticas previsiones contiene el artículo 83.2 de la Ley 4/2006, de 19 de mayo, de Conservación de la Naturaleza de Cantabria — “Será pública la acción para exigir ante las Administraciones Públicas la observancia de lo

${ }^{29}$ GARCÍA URETA, "El Convenio de Aarhus: derechos de..." cit., p. 84,

${ }^{30}$ LÓPEZ SÁNCHEZ, J., "La legitimación procesal en materia de medio ambiente", Embid Irujo, A. (dir.), El derecho a un medio ambiente adecuado, lustel, Madrid, 2008, p. 389. 
establecido en la presente Ley y disposiciones de desarrollo y aplicación"-, el artículo 61 de la Ley 11/1994, de 27 de diciembre, de espacios naturales protegidos de la Comunidad Valenciana - "Será pública la acción para exigir, ante los órganos administrativos, el cumplimiento de lo establecido en esta Ley y las normas y planes que la desarrollen y ejecuten"- y el artículo 38 de la Ley 12/1985, de 13 de junio, de Espacios Naturales de Cataluña - "Será pública la acción para exigir el cumplimiento de lo establecido por la presente Ley y las normas y planes que la desarrollan"-.

La Ley 5/1991, de 5 de abril, de Protección de los Espacios Naturales, del Principado de Asturias, va más allá, al señalar lo siguiente: "Será pública la acción para exigir ante los órganos administrativos la observancia de lo dispuesto en esta Ley, las normas que la desarrollen, los planes de ordenación de los recursos naturales, las normas de los espacios naturales protegidos, y los planes rectores de uso y gestión".

Más completa es la regulación del artículo 109 de la Ley 7/1995, de 21 de abril, de la fauna silvestre, caza y pesca fluvial, de la Región de Murcia, con un apartado segundo referido a los procedimientos administrativos sancionadores en el que no termina de quedar claro si lo previsto en su apartado primero se circunscribe solo a estos o a la posibilidad de actuar frente a cualquier otro incumplimiento de la ley, incluso realizado por la propia Administración, ajeno a cualquier procedimiento sancionador:

1. Será pública la acción para exigir ante las administraciones públicas la observancia de lo establecido en esta Ley y en las disposiciones que se dicten para su desarrollo y aplicación.

2. Para que pueda darse la tramitación oportuna a la acción pública ejercida por los particulares, éstos deberán fundamentar suficientemente los hechos que supongan la infracción. Si la Administración considera que no existen pruebas suficientes, se archivará el expediente una vez realizadas por la misma las investigaciones oportunas.

Esta previsión contenida en la citada Ley de la fauna silvestre, caza y pesca fluvial de la Región de Murcia tuvo mucho éxito en la posterior legislación protectora del mundo biótico de otras comunidades autónomas al ser reproducida por varias de ellas de manera idéntica. Así, también se prevé en el 
artículo 43 de la Ley Foral 9/1996, de 17 de junio, de Espacios Naturales de Navarra; en el artículo 110 de la Ley Foral 2/1993, de 5 de marzo, de protección y gestión de la fauna silvestre y sus hábitats; en la disposición adicional segunda de la Ley 8/1998, de 26 de junio, de Conservación de la Naturaleza y de Espacios Naturales de Extremadura; y también en el artículo 76 de la Ley 4/2003, de 26 de marzo, de Conservación de Espacios Naturales de La Rioja.

Como se ve en estos ejemplos, aunque hay algunos más en la profusa legislación sectorial autonómica, la heterogeneidad de las disposiciones que reconocen la denominada acción pública en materia ambiental es grande. Unas la reconocen con anterioridad a la LIPPJMA en su sentido más amplio (administrativa y judicial), otras parecen circunscribirla al ámbito de los recursos administrativos y otras la refieren a los procedimientos administrativos sancionadores, aunque no dejan claro si se refieren exclusivamente a la posibilidad de denunciar determinadas infracciones o bien a la posibilidad de personarse en un procedimiento administrativo sancionador frente al presunto infractor.

Esto constituye, como señala JORDANO FRAGA, "una paradoja ilustrativa de lo absurdo que es defender un sistema de legitimación inadmisible en un Estado social y democrático de derecho"31. A juicio de QUINTANA LÓPEZ, es una vez más a través de la competencia para dictar normas adicionales de protección de que disponen las CC. AA. como ha llegado la acción pública al derecho ambiental $^{32}$.

A mi juicio, no hay reflexión seria en las previsiones citadas. En unas porque invaden la competencia procesal, que es exclusiva del Estado por mor del artículo $149.1 .6^{\circ}$ y porque no sería de recibo que lo que es recurrible en una comunidad autónoma ante los tribunales no lo fuese en la comunidad autónoma vecina, y más cuando estamos ante el ejercicio de un derecho fundamental como es el derecho a la tutela judicial efectiva, reconocido en el artículo 24 de la Constitución.

\footnotetext{
31 JORDANO FRAGA, J., La protección del derecho a un medio ambiente adecuado, Bosch, Barcelona, 1995, p. 333.

${ }^{32}$ QUINTANA LÓPEZ, T., "Legitimación procesal y defensa del ambiente", RADA, núm. 4, 2003, p. 142, si bien el mismo autor es más partidario de que fuese el legislador estatal el que la reconociera a través de la legislación sectorial.
} 
En otros casos, se reconoce la denominada acción pública en vía administrativa para recurrir ante los órganos administrativos las posibles vulneraciones de la legislación ambiental. Tampoco tiene mucho sentido, y sería absurdo reconocer la legitimación en vía administrativa exclusivamente porque, si alguien está legitimado en vía administrativa para recurrir un acto, lo normal es que, ante una desestimación expresa o presunta del acto que recurre, se reconozca también la legitimación para recurrirlo en vía contencioso-administrativa, con lo que indirectamente también se está reconociendo el ejercicio de una acción pública en vía judicial. En particular, reconocida en vía administrativa la legitimación activa, como regla general debe admitirse en el proceso contenciosoadministrativo. Así lo ha venido reconociendo la jurisprudencia; como señala la Sentencia del Tribunal Supremo de 22 de abril de 2002, esta circunstancia no resulta inocua porque, como viene señalando esta sala, la Administración no puede aducir la falta de legitimación que ella misma ha admitido. En el mismo sentido, las sentencias del Tribunal Supremo de 17 de febrero de 2001, de 23 de febrero de 1999, de 9 de marzo de 2006 y de 21 de diciembre de $2000^{33}$.

Pese a lo señalado, hay resoluciones judiciales que incomprensiblemente, argumentando la falta de interés legítimo del recurrente, niegan la legitimación a quien la ha tenido en vía administrativa para impugnar un acto; lo que aún tiene menos sentido es que, si la propia Administración ha admitido la legitimación de una persona en la vía administrativa de recurso, plantee la excepción de falta de legitimación cuando la cuestión se trata de ver ante los órganos judiciales del orden jurisdiccional contencioso-administrativo. A mi juicio, una Administración que reconoció en vía administrativa la legitimación no puede negarla en vía judicial, so pena de atentar contra los actos propios y, por lo tanto, contra la buena fe.

Entiendo que la legitimación no supone un mayor problema salvo cuando estamos ante proyectos que son autorizados por ley; en este caso la efectividad de la tutela judicial desaparece al quedar solo abierta la posibilidad del recurso de inconstitucionalidad directo o que un juez plantee una cuestión cuando tiene que aplicarla a la ratio decidendi de su sentencia, una forma de eludir el control

${ }^{33}$ CHAVES GARCÍA, J. R. y GALINDO GIL, M. D., Diccionario jurisprudencial del proceso contencioso-administrativo, 2. ${ }^{\text {a }}$ ed., Wolters Kluwer, 2018, p. 258. 
judicial ordinario mediante recurso a la que se ha recurrido por desgracia en más de una ocasión, como así se destaca en el estudio sobre el acceso a la justicia ambiental, que cubre el período 2012-2013, Effective Justice? Synthesis report of the study on the Implementation of Articles 9.3 and 9.4 of the Aarhus Convention in the Member States of the European Union.

Si bien nuestra jurisprudencia constitucional ha puesto ciertos límites, no llega a rechazar de forma tajante esta práctica ante situaciones excepcionales, habiendo dictado, entre otras, las SSTC 203/2013 (sobre la Ley 6/2007, de 28 de marzo, de aprobación del Proyecto Regional "Ciudad del Medio Ambiente", de Castilla y León), 50/2015 (sobre la Ley 5/2010, de 28 de mayo, de modificación de la Ley 4/2000, de 27 de junio, de declaración del Parque Natural de Fuentes Carrionas y Fuente Cobre-Montaña Palentina, de Castilla y León), 231/2015 (que resuelve la cuestión de constitucionalidad en relación con la DA

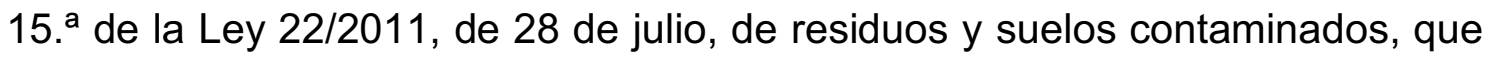
prevé la convalidación de actuaciones realizadas al amparo del Real Decreto 1419/2005, de 25 de noviembre) y 269/2015 (que resuelve una cuestión de inconstitucionalidad planteada por el TSJ de Castilla y León en relación con la Ley $2 / 2008$, de 17 de junio, de declaración de proyecto regional para la instalación de un centro de tratamiento de residuos industriales no peligrosos en el término municipal de Fresno de la Ribera) $)^{34}$. Como señala SANTAMARÍA ARINAS, a la vista de esta jurisprudencia: "De cara al futuro, aparentemente, se mantiene la afirmación de que las leyes singulares autoaplicativas no están prohibidas en el sistema constitucional español. Pero resulta una afirmación retórica si se tiene en cuenta que esa posibilidad se rodea con límites que son cada vez más estrechos"35. En este sentido, a nivel comunitario, debe también destacarse la doctrina Boxus, del TJUE, en virtud de la Sentencia de 18 de octubre de 2011, que deja a las claras que "el artículo 9 del Convenio de Aarhus y el artículo 10 bis de la Directiva 85/337 perderían, sin embargo, todo efecto útil si el sólo hecho de adoptarse un proyecto mediante un acto legislativo que no se ajustase a los requisitos a que se ha hecho referencia en el apartado

\footnotetext{
${ }^{34}$ Tal y como destaca VALENCIA MARTIN, G., Jurisprudencia constitucional y medio ambiente, Aranzadi, Pamplona, 2017, p. 217 y ss. Sobre algunas de estas sentencias, véase también SANTAMARÍA ARINAS, R. J., "Leyes singulares, tutela judicial efectiva y recepción de la doctrina Boxus por el Tribunal Constitucional español", RAP, 193, 2014.

${ }^{35}$ SANTAMARÍA ARINAS, "Leyes singulares..." cit, p. 189.
} 
37 de la presente sentencia tuviese como consecuencia sustraerlo a cualquier posible recurso dirigido a impugnar su legalidad, en cuanto al fondo o en cuanto al procedimiento, en el sentido de dichos textos"36.

\section{LOS OBSTÁCULOS AL ACCESO A LA JUSTICIA AMBIENTAL SIGUEN SIENDO LOS MISMOS VEINTE AÑOS DESPUÉS: PRINCIPALMENTE ECONÓMICOS}

Vistas algunas cuestiones relativas a la legitimación, los diferentes obstáculos residen principalmente en el ámbito de la justicia gratuita y en el establecimiento de las medidas cautelares y contracautelas que, en su caso, se estipulen. Aquí es donde está el problema, no en la mayor o menor interpretación de la amplia legitimación.

El Convenio de Aarhus reconoce que, para el ejercicio de los derechos derivados de su articulado, los ciudadanos pueden necesitar asistencia. Entre esa asistencia, tiene un papel destacado la asistencia económica, especialmente cuando hablamos de la posibilidad de acceso a la justicia, que suele llevar aparejados una serie de costes. Al respecto, en su articulado, el Convenio de Aarhus señala que los procedimientos en materia de participación y las acciones relativas a la infracción del derecho ambiental nacional "deberán ofrecer recursos suficientes y efectivos [...] y deberán ser objetivos, equitativos y rápidos sin que su costo sea prohibitivo" (artículo 9.4), y exige a los Estados que prevean el establecimiento de mecanismos apropiados de asistencia encaminados a eliminar o reducir los obstáculos financieros o de otro tipo que traben a la justicia (artículo 9.5) ${ }^{37}$.

\footnotetext{
${ }^{36}$ Sobre esta sentencia y su problemática, GARCíA URETA, A., "Convenio de Aarhus y convalidaciones legislativas: ¿ ¿Recurso directo contra leyes en vía contenciosa? Comentario a la sentencia del TJUE (Gran Sala) de 18 de octubre de 2011, Boxus v. Regione Wallone, asuntos acumulados C-128/09 a C-131/09, C134/09 y C-135/09", Diario La Ley, 7763, 27 de diciembre de 2011; PERNAS GARCÍA, J. J., "La aprobación o convalidación por norma con rango de Ley de proyectos sometidos a evaluación ambiental y su control de validez a la luz de la jurisprudencia del TJUE", RVAP, núm. 104, 2016.

${ }^{37}$ Sobre estos obstáculos, PEÑALVER i CABRÉ, La defensa... cit., pp. 485-543, y HERNÁNDEZ ARAYA, N. A., "Barreras económicas en el acceso a la justicia ambiental en España", RADA, núm. 36, 2017, quien, siguiendo al anterior, propugna como soluciones a los problemas modificar su régimen actual. En concreto, la asistencia jurídica gratuita, la modificación del régimen de condena en costas y la modificación del régimen de medidas cautelares, es decir, todos los obstáculos económicos.
} 
En España se ponen de manifiesto como principales problemas en cuanto al acceso a la justicia ambiental los costes y la lentitud de los procesos judiciales y el hecho de que determinados proyectos sean aprobados por ley, lo que no los hace recurribles por los ciudadanos, así como la inefectividad del sistema legal ${ }^{38}$.

En este sentido, una reciente comunicación de la Comisión Europea ${ }^{39}$ señala la necesidad de adoptar las medidas necesarias para garantizar que el coste de las acciones legales en relación con la legislación medioambiental de la UE no sea prohibitivo y esté en consonancia con los requisitos del derecho de la UE y el Convenio de Aarhus.

El Documento de trabajo de la Comisión sobre la revisión de la aplicación del derecho ambiental en España ${ }^{40}$ señala que llevar ante los tribunales causas administrativas parece ser caro y que el coste previsto puede impedir que los ciudadanos lleven asuntos a los tribunales, no siendo el programa ya existente de asistencia jurídica suficiente para compensar los elevados costes.

Por ello, propone adoptar las medidas necesarias para garantizar que el coste de las acciones legales en relación con la legislación medioambiental de la UE no sea prohibitivo y esté en consonancia con los requisitos del derecho de la UE y del Convenio de Aarhus.

Téngase en cuenta que el coste del proceso ambiental puede ser muy elevado habida cuenta de los informes técnicos, la articulación de la prueba y el riesgo cierto de una condena en costas ante una eventual desestimación de las pretensiones.

\section{La asunción de las costas procesales}

El primero de los elementos disuasorios para entablar una acción judicial lo constituye el riesgo de ser condenado a abonar las costas procesales del litigio, propias y de la otra parte, en caso de desestimación del recurso, tal y como prevé la LJCA.

\footnotetext{
${ }^{38}$ Estudio sobre el acceso a la justicia ambiental, 2012-2013, Effective Justice? Synthesis report of the study on the Implementation of Articles 9.3 and 9.4 of the Aarhus Convention in the Member States of the European Union, 2013-10-11/Final, p. 50.

${ }^{39} \operatorname{COM}(2016) 316$ final.

${ }^{40}$ SWD(2017) 42 final, 03.02.2017.
} 
En este sentido, debiera articularse la eliminación de tal condena cuando las pretensiones no sean particulares sino estrictamente ambientales, ya que, de lo contario, supone un importante elemento disuasorio para el ejercicio de cualquier acción ambiental frente a la actuación de las Administraciones públicas.

No obstante, el artículo 8.3 in fine del Convenio de Aarhus establece lo siguiente:

Cada Parte velará porque las personas que ejerzan sus derechos de conformidad con las disposiciones del presente Convenio no se vean en modo alguno penalizadas, perseguidas ni sometidas a medidas vejatorias por sus actos. La presente disposición no afectará en modo alguno al poder de los tribunales nacionales de imponer costas en una cuantía razonable al término de un procedimiento judicial.

Como señala PEÑALVER i CABRÉ, la exoneración de la condena en costas ha sido aplicada pese a la desestimación de recursos contencioso-administrativos cuando se ha tratado de recursos contra reglamentos o actos administrativos relativos a sectores que cuentan con una legislación compleja, como en el caso de la STS de 25 de abril de 2016, que desestima el recurso planteado por varias asociaciones ecologistas en relación con el fracking, mientras que en otros casos, si bien se condena en costas a ONG ambientales que recurren contra actos o reglamentos con base en la acción pública ambiental, las cantidades no suelen superar los $3.000 €^{41}$, con lo que el coste no parece ser muy excesivo.

En otros casos, la ONG recurrente ha sido beneficiaria; en este sentido, la STS de 13 de octubre de 2016 determina, de conformidad con el artículo 36.1 de la Ley 1/1996, de 10 de enero, de asistencia jurídica gratuita, que la asociación Ecologistas en Acción de Segovia es beneficiaria de la condena en costas de tres mil euros más el IVA correspondiente por los aranceles del procurador y los honorarios del abogado de dicha asociación.

Como ya se ha dicho, nuestra ley de la jurisdicción contencioso-administrativa establece en su artículo 139 que, en primera o única instancia, el órgano

\footnotetext{
${ }^{41}$ Estudio sobre el acceso a la justicia ambiental, 2012-2013, Effective Justice? Synthesis report of the study on the Implementation of Articles 9.3 and 9.4 of the Aarhus Convention in the Member States of the European Union, 2013-10-11/Final, p. 18. En el mismo sentido, PEÑALVER i CABRÉ, A. "Acceso a la justicia ambiental: aspectos principales de la jurisprudencia contenciosoadministrativa", Observatorio de políticas ambientales, 2017, CIEDA-Ciemat, Madrid, 2017, pp. 419-420.
} 
jurisdiccional impondrá las costas a la parte que haya visto rechazadas todas sus pretensiones, salvo que aprecie, y así lo razone, que el caso presentaba serias dudas de hecho o de derecho. Una cuestión, la de las costas, que tampoco ha sido ajena en el ámbito de la justicia ambiental a la consideración del TJUE y en particular a que no se incurra en "coste prohibitivo" para el recurrente, debiendo tenerse en cuenta la situación financiera del interesado, el hecho de que el demandante tenga una posibilidad de éxito razonable, la importancia de lo que está en juego para el demandante y para el medio ambiente, la complejidad de la legislación aplicable y del procedimiento, y, por último, el posible carácter temerario del recurso.

Ya el propio TJUE ${ }^{42}$ ha tenido ocasión de pronunciarse en este punto, señalando que "se debe tener en cuenta la capacidad económica del interesado, pero no sólo ello, sino que debe basarse en un análisis objetivo de la cuantía de las costas, única forma en la que los particulares y las asociaciones podrán desempeñar un papel activo en la defensa del medio ambiente. Eso quiere decir que el coste de un procedimiento no debe resultar objetivamente irrazonable". Por consiguiente, el coste de un procedimiento no debe superar la capacidad financiera del interesado, y siempre debe ser razonable desde un punto de vista objetivo ${ }^{43}$.

De hecho, de acuerdo con la Comunicación de la Comisión Europea sobre el acceso a la justicia, los Estados miembros deben garantizar que los procedimientos de control jurisdiccional en los que se impugnen decisiones, actos y omisiones relativos a la legislación ambiental de la UE no tengan un coste prohibitivo, de forma que no constituyan un elemento disuasorio a la hora de impugnar un acto administrativo, debiendo tener los demandantes derecho a una previsibilidad razonable en lo relativo a los gastos procesales, teniéndose en cuenta los costes de representación letrada, las tasas judiciales, los costes de las pruebas y las tasas de los expertos.

La reciente STJUE de 15 de marzo de 2018, asunto C-470/2016, resuelve sobre la imposición de las costas (513.000 euros) del procedimiento judicial incoado

\footnotetext{
42 STJUE de 11 de abril de 2013, asunto C-260/11, Pallikaropoulos (y otro)/Environment Agency y otros. Sobre esta sentencia, GARCÍA URETA, "Acceso a la justicia..." cit.

43 STJUE, de 13 de febrero de 2014, asunto C-530/11, Comisión c. Reino Unido.
} 
por las demandantes para obtener la autorización necesaria para interponer recurso judicial, que fue desestimado por prematuro. El juez irlandés, al dudar sobre la aplicación de la regla de la "onerosidad no excesiva", planteó siete cuestiones prejudiciales. En respuesta a ellas, el TJUE establece en resumen que las partes contratantes del Convenio de Aarhus pretendían inequívocamente aplicar la protección contra los costes prohibitivos a los recursos cuyo objeto consista en hacer respetar la legalidad medioambiental en abstracto, sin supeditar dicha protección a la prueba de un vínculo cualquiera con un daño al medio ambiente real o, a fortiori, potencial, y que un Estado miembro no puede disponer excepciones a la exigencia -establecida en el artículo 9, apartado 4, del Convenio de Aarhus y en el artículo 11, apartado 4, de la Directiva 2011/92de que determinados procedimientos no sean excesivamente onerosos cuando se considere que un recurso se ha interpuesto con temeridad o mala fe o cuando no exista un vínculo entre la infracción del derecho medioambiental nacional que se alega y un daño al medio ambiente. Ahora bien, como señala REVUELTA en comentario a dicha sentencia, esta no afecta a la facultad de los órganos judiciales de imponer las costas a los demandantes en casos de temeridad o mala fe, en los términos previstos en el Convenio de Aarhus; sin embargo, en tal caso, las costas nunca podrán ser demasiado onerosas, sino "razonables" 44 .

\section{El necesario acceso a la justicia gratuita}

Ya he señalado que uno de los principales problemas de los procesos ambientales y de su acceso en condiciones lo constituye su posible elevado coste tanto por la dificultad probatoria como por la necesidad de informes y la intervención de peritos.

En este sentido, el artículo 23.2 LIPPJMA realiza una remisión en cuanto a las personas jurídicas como beneficiarias del acceso a la justicia gratuita: "Las personas jurídicas sin ánimo de lucro a las que se refiere el apartado anterior tendrán derecho a la asistencia jurídica gratuita en los términos previstos en la Ley 1/1996, de 10 de enero, de Asistencia Jurídica Gratuita".

\footnotetext{
${ }^{44}$ REVUELTA PÉREZ, I., Actualidad Jurídica Ambiental, abril 2018.
} 
Una remisión que, como señala NOGUEIRA LÓPEZ, cayó en saco roto, puesto que la Ley 2/2017, de 21 de junio, de modificación de la Ley 1/1996, de 10 de enero, de asistencia jurídica gratuita, no recogió esa extensión del beneficio a las asociaciones ecologistas, ya que este sigue condicionado a que acrediten la falta de ingresos y a la declaración de utilidad pública ${ }^{45}$.

El hecho de que no se esté garantizando de forma adecuada el acceso a la justicia gratuita en materia ambiental en España se pone de manifiesto en el Informe de 28 de julio de 2017 del Comité de Cumplimento del Convenio de Aarhus, en el que se insta a adoptar las medidas necesarias para que el cumplimiento del Convenio sea efectivo ${ }^{46}$, recomendaciones que se reiteran en el Informe del mismo Comité de Cumplimiento de 10 de enero de $2018^{47}$. En concreto, el Comité ya había lamentado que no se hubieran tomado medidas reales para remover los obstáculos existentes para la plena aplicación de los párrafos 4 y 5 del artículo 9 del Convenio con respecto de la asistencia jurídica gratuita a las ONG, no considerando suficiente confiar en las comisiones de asistencia jurídica, a lo que el Reino de España alegó que era necesario modificar la legislación con un nuevo proyecto de ley, pero que ello no había sido posible debido a la inexistencia de Gobierno durante trescientos días. Finalmente, el Comité recomienda a España que adopte medidas, con carácter de urgencia, para garantizar que los obstáculos restantes a la plena aplicación del artículo 9, párrafos 4 y 5 de la Convención con respecto a la asistencia letrada para ONG, a la vez que exhorta a todos los ministerios pertinentes, incluido el Ministerio de Justicia, para trabajar juntos en ese sentido. Finalmente, exige al Reino de España que proporcione informes detallados de progreso al Comité, a más tardar el 1 de octubre de 2018, el 1 de octubre de 2019 y el 1 de octubre de 2020, sobre las medidas adoptadas y los resultados logrados en la implementación de tales recomendaciones. De momento, no tenemos noticia de que se haya aprobado anteproyecto o proyecto de ley alguno en este sentido.

\footnotetext{
${ }^{45}$ NOGUEIRA LÓPEZ, "Pack Premium..." cit., p. 317.

${ }^{46} \mathrm{www}$.unece.org/fileadmin/DAM/env/pp/mop6/Documents_aec/ece.mp.pp.2017.43_auec.pdf

${ }^{47}$ www.unece.org/fileadmin/DAM/env/pp/mop6/English/ECE__MP.PP_2017_2_Add.1_E.pdf
} 
La cuestión fundamental que desde el punto de vista del ordenamiento jurídico español se plantea es cómo interpretar la remisión que el artículo 23.2 de la LIPPJMA realiza a la Ley de Asistencia Jurídica Gratuita.

Son numerosas las ocasiones en las que colegios de abogados y comisiones provinciales de asistencia jurídica gratuita han denegado solicitudes de acceso a la justicia gratuita por parte de ONG, pese a cumplir los requisitos de la LIPPJMA para el ejercicio de la acción pública ambiental, por no acreditar la insuficiencia de medios o recursos para litigar o no adjuntar la correspondiente declaración de utilidad pública.

En mi opinión, si realmente se quiere implementar lo previsto en el artículo 23.2 de la LIPPJMA y su espíritu, debiera ser suficiente para ser beneficiario de la justicia gratuita la acreditación de los requisitos de legitimación. En este sentido, el Comité de Cumplimiento del Convenio de Aarhus ya advirtió que el sistema español de asistencia jurídica resultaba muy restrictivo para las pequeñas ONG y que exigir el cumplimiento de unos requisitos económicos imprescindibles para ser declaradas asociaciones de utilidad pública y, en consecuencia, poder recibir la asistencia gratuita resultaba contradictorio con el concepto mismo de asistencia jurídica, que lo que persigue justamente es facilitar el acceso a la justicia a los económicamente más débiles. La interpretación correcta, por lo tanto, ya asumida por algunos tribunales, es que "la justicia gratuita viene atribuida por disposición legal a las asociaciones que cumplan con los requisitos del artículo 23.1 de la Ley 27/2006. No es necesario acreditar otros requisitos, que lo único que hacen es obstaculizar el acceso a la justicia"48.

Esto era algo que ya venía siendo exigido por la doctrina, y es que, de acuerdo con lo establecido en el Convenio de Aarhus, la solución que ha adoptado la LIPPJMA en este punto ha sido la de hacer acreedores del beneficio de la justicia gratuita a las ONG ambientales, si se tiene en cuenta que tanto el Convenio sobre reconocimiento de la personalidad jurídica de las ONG como la Directiva 2003/35/CE y la LIPPJMA establecen como requisito que no tengan ánimo de lucro. Para evitar algunos de estos obstáculos económicos a las ONG, la

\footnotetext{
${ }^{48}$ Así lo señala el Informe presentado por el Ministerio de Agricultura y Medio Ambiente a la Reunión de las Partes:

http://www.mapama.gob.es/es/ministerio/servicios/participacionpublica/Borrador_estudio_acces o_justicia_medioambiental_tcm7-303662.pdf-
} 
LIPPJMA otorga a estas asociaciones el beneficio de la justicia gratuita en los términos previstos en la citada Ley 1/1996, de 10 de enero, algo que sin duda trata de no disuadir ni entorpecer el acceso a la justicia de este tipo de ONG y que no debe ser objeto de interpretación restrictiva ${ }^{49}$.

La jurisprudencia en España, mediante diferentes autos, ya ha ido resolviendo precisamente algunos recursos en relación con el beneficio de justicia gratuita para las ONG ambientales cuando entablan procesos judiciales ambientales.

Es el caso del Auto del TSJ de Extremadura, de 22 de abril de 2013, que "acepta el planteamiento de la Asociación ecologista impugnante que viene a sostener que es una entidad beneficiaria del derecho a justicia gratuita por expresa disposición legal, por así disponerlo el artículo 23.2 la Ley 27/2006, por la que se regula los derechos de acceso a la información, de participación pública y de acceso a la justicia en materia de medio ambiente", o del Auto 174/2013, de 15 de mayo, del Juzgado de lo Contencioso-Administrativo núm. 6 de Murcia.

El Auto revoca la denegación del derecho a la justicia gratuita solicitado por Ecologistas en Acción. Como señala DORESTE HERNÁNDEZ, sienta un importante precedente en esta materia hasta ahora nada pacífica, en la que las distintas comisiones provinciales de asistencia jurídica gratuita han mostrado que no han interiorizado el alcance el artículo 23.2 LIPPJMA ${ }^{50}$. En concreto, el citado auto señala lo siguiente:

[...] la Sala acepta el planteamiento de la Asociación ecologista impugnante que viene a sostener que es una entidad beneficiaria del derecho a justicia gratuita por expresa disposición legal, por así disponerlo el artículo 23.2 la Ley 27/2006, por la que se regula los derechos de acceso a la información, de participación pública y de acceso a la justicia en materia de medio ambiente. $Y$ es que, incuestionado que concurren en ella los requisitos exigidos en el $n^{0} 1$ del mencionado artículo, compartimos los argumentos que sustentan el planteamiento, especialmente el que viene a decir que hay que rechazar toda interpretación que conduzca a hacer inútil o innecesaria una norma, principio que constituye doctrina jurisprudencial pacífica, de la que es buena muestra la STS (Pleno) de 5 de noviembre de 2008.

${ }^{49}$ RAZQUIN LIZARRAGA y RUIZ DE APODACA ESPINOSA, Información, participación... cit., pp. 408-409.

${ }_{50}$ DORESTE HERNÁNDEZ, J., Actualidad Jurídica Ambiental, julio de 2013. 
En cuanto a las extintas tasas judiciales, el Auto del Tribunal Supremo de 30 de octubre de 2014 entendió, no obstante, que las tasas de acceso a la justicia para el recurso de casación por parte de una ONG debían ser pagadas, lo que no vulneraba el artículo 9 del Convenio de Aarhus:

[...] la jurisprudencia que sobre dicho precepto invoca el recurrente con las sentencias aportadas, se limita a señalar la necesidad de que los costes del proceso no sean excesivamente onerosos, condición que no cabe atribuir a la tasa judicial singularmente y aisladamente considerada en la medida en la que, como ya ha quedado expuesto, su regulación nacional impide que se la pueda considerar como un obstáculo que dificulte el acceso al proceso.

Afortunadamente, el Tribunal Constitucional, en su Sentencia 140/2016, dictada posteriormente, no lo entendió así, y anuló lo previsto en la Ley 10/2012, de 20 de noviembre, por la que se regulan determinadas tasas en el ámbito de la Administración de Justicia y del Instituto Nacional de Toxicología y Ciencias Forenses, que estableció las citadas tasas para el ejercicio del acceso a la justicia.

\section{La batalla de las medidas cautelares. Cautelas y contracautelas que dificultan la justicia ambiental}

Justicia tardía, justicia baldía. Es esta una afirmación que late con fuerza en todos los procesos y, por supuesto, con más razón en los procesos ambientales, en los que la tardanza en la resolución de los procedimientos judiciales pone de manifiesto claramente el denominado periculum in mora, que justifica la necesaria adopción de las medidas cautelares cuando estas sean solicitadas por los recurrentes. De lo contrario, cualquier proyecto anulado puede haber sido perfectamente ejecutado, consumarse el impacto ambiental y resultar imposible la ejecución de la sentencia.

La Comunicación de la Comisión Europea sobre el acceso a la justicia ambiental señala que un órgano jurisdiccional nacional que conozca de un litigio regulado por la legislación ambiental de la UE debe poder inaplicar una decisión o acto impugnados o establecer medidas positivas antes de emitir su sentencia, debiendo valorar los intereses en juego. 
El acceso a la justicia cautelar en asuntos de incidencia medioambiental encuentra su fundamento, además, en los principios propios del derecho ambiental, como son el principio de prevención y el principio de precaución.

En este punto, dentro de los procesos ambientales la casuística es amplia y en cada uno de ellos los jueces y tribunales se guían por los criterios que la LJCA determina y cuya concurrencia o no corresponde valorar en cada caso. Estos son el periculum in mora y la ponderación de los intereses en conflicto, a los que se suma con un carácter excepcional el fumus boni iuris o apariencia de buen derecho.

El artículo 130 LJCA señala que, previa valoración circunstanciada de todos los intereses en conflicto, la medida cautelar podrá acordarse únicamente cuando la ejecución del acto o la aplicación de la disposición pudieran hacer perder al recurso su finalidad legítima.

El periculum in mora, o pérdida de la finalidad legítima del recurso en caso de no adoptarse la medida cautelar solicitada, es conditio sine qua non para poder estimar una medida cautelar de suspensión, y es lo que siempre concurre en los procedimientos judiciales ambientales en los que se pide tal medida. Es obvio que, si entendemos que un proyecto o infraestructura es gravemente perjudicial para el medio ambiente, en caso de no accederse a tal medida y ejecutarse la obra, de nada servirá una sentencia estimatoria que confirme los argumentos contenidos en la demanda. De ahí que la cuestión suela plantearse en sede de la ponderación de los intereses en conflicto y que la respuesta sea variada.

En cuanto a la ponderación de los intereses en conflicto, es aquí donde se plantean los mayores problemas, dado que en muchos proyectos con incidencia ambiental confluyen grandes intereses económicos, de desarrollo, sociales e incluso políticos, lo que hace muy difícil la estimación de la medida cautelar de suspensión de la autorización por la que se permite la realización del proyecto.

Por otro lado, dado que los actos administrativos autorizatorios se presumen válidos y eficaces y han sido dictados previo procedimiento administrativo, con participación y cumpliendo la preceptiva evaluación ambiental en la mayoría de los casos, resulta difícil que la valoración de los intereses en conflicto recaiga sobre el aspecto ambiental, puesto que se considera que esa valoración ya la ha 
realizado la propia Administración autorizante antes de autorizar el proyecto ahora discutido.

Ahora bien, cada vez más la jurisprudencia viene reconociendo el interés público ambiental como un interés prevalente en muchos casos en los que, recurriendo al periculum in mora acreditado y realizando una ponderación circunstanciada de los intereses en conflicto, accede a otorgar, sobre la base de los principios antes referidos de prevención y de precaución, las medidas cautelares solicitadas por las ONG ambientales en los procesos contenciosoadministrativos entablados ${ }^{51}$.

Como señala José Antonio RAZQUIN LIZARRAGA, del análisis de la jurisprudencia más reciente puede deducirse la primacía del interés público medioambiental sobre el interés urbanístico, sobre el interés privado, teniendo en cuenta la difícil o imposible reversibilidad de los daños al medio ambiente y la consideración de la posición de las Administraciones públicas en conflicto, dándose preponderancia a los intereses de la Administración superior frente a otra inferior (Estado frente a comunidad autónoma o ente local, y comunidad autónoma frente a entidad local) ${ }^{52}$.

Como señala el reciente Auto de 4 de enero de 2017 del TSJ de Canarias, en relación con la solicitud de suspensión cautelar de la ejecución de las obras de construcción e instalación de la línea de transporte a 132 kV entre Puerto del Rosario y Gran Tarajal:

Pues bien, entendemos que en este caso la actuación administrativa no se ajustó a los parámetros que conforman el principio de cautela, el cual, tal como se ha indicado, constituye un mandato de actuación a los poderes públicos en orden a la adopción de las medidas de protección necesarias, inclusive en aquellos supuestos en que ni siquiera exista plena certeza científica acerca de los efectos perjudiciales de un determinado fenómeno en el medio ambiente o la salud de las personas (entre otras, Sentencia del Tribunal de Justicia de las Comunidades Europeas de 5 de mayo de 1998, Reino Unido/Comisión, C-180/96 ) y a cuya luz

\footnotetext{
${ }^{51}$ Entre otras, STS de 11 de febrero de 2009, STS de 23 de julio de 2009, STS de 20 de octubre de 2010 y STS de 16 de julio de 2012.

52 RAZQUIN LIZARRAGA, J. A., "Las medidas cautelares en el proceso ContenciosoAdministrativo respecto del medio ambiente en la reciente jurisprudencia del Tribunal Supremo", Revista Aranzadi Doctrinal, núm. 3, 2010.
}

[DOI. 10.17345/2410] 
debe interpretarse la normativa ambiental (en este sentido, Sentencia de 7 de septiembre de 2004, C127/02 en relación con la Directiva hábitats). En definitiva este principio de precaución tiene su fundamento en la irreparabilidad de los daños al medio ambiente. Por aplicación de tal doctrina debemos dar preferencia a los posibles perjuicios que se puedan seguir para el medio ambiente y por ello acordar la suspensión solicitada por el Cabildo demandante ${ }^{53}$.

Aquí, evidentemente, no acaban los problemas. Pese a haberse podido obtener una resolución judicial favorable sobre la medida cautelar solicitada, no es extraño que puedan establecerse las correspondientes contracautelas, consistentes en garantías financieras de aseguramiento que puedan ser exigidas al recurrente en el caso de que la sentencia sea desestimatoria en cuanto al fondo. Sin duda, este constituye un obstáculo insalvable para los recurrentes, especialmente si se trata de proyectos de infraestructura en los que la valoración del coste de demora mientras se sustancia el pleito puede ser muy elevada.

La exigencia de caución a las asociaciones ambientalistas determina la impracticabilidad de la adopción de medidas cautelares, ya que carecen de esas elevadas cantidades. A juicio de JORDANO FRAGA, la barrera económica en la justiciabilidad de las decisiones administrativas que inciden sobre el medio ambiente encuentra respaldo en la jurisprudencia del $\mathrm{TS}^{54}$.

Aquí es donde se plantea un importante problema y es el hecho de que el artículo 133 establece que, cuando de la medida cautelar pudieran derivarse perjuicios de cualquier naturaleza, podrán acordarse las medidas que sean adecuadas para evitar o paliar dichos perjuicios. Igualmente, podrá exigirse la presentación de caución o garantía suficiente para responder de aquellos, que podrá constituirse en cualquiera de las formas admitidas en derecho. Como es de suponer, estas garantías o cauciones pueden ser de una cantidad elevada que

\footnotetext{
${ }^{53}$ DORESTE HERNÁNDEZ, J., "El principio de precaución, Convenio de Aarhus y las medidas cautelares en el procedimiento contencioso-administrativo: Comentario de los autos de 4 de enero y 9 de marzo de 2017, de la sección segunda de la sala de lo contencioso-administrativo del Tribunal Superior de Justicia de Canarias", Actualidad Jurídica Ambiental, núm. 69, 5 de junio de 2017.

54 JORDANO FRAGA, J., "El proceso de afirmación del medio ambiente como interés público prevalente o la tutela ambiental cautelar efectiva: la suspensión de los actos administrativos por razón de la protección del medio ambiente en la jurisprudencia del TS”, RAP, núm. 145, 1998, p. 187.
} 
haga inviable para una ONG o cualquier interesado en un pleito ambiental poder asumirla.

Ahora bien, por mor del artículo 9.4 del Convenio de Aarhus, que señala que los recursos en materia de medio ambiente deben incluir la posibilidad de adoptar medidas cautelares suficientes y efectivas, que han de ser objetivas, equitativas y rápidas, sin que su coste sea prohibitivo, el concepto de coste prohibitivo es un concepto jurídico indeterminado que los jueces o tribunales deben determinar.

Ahora bien, lo cierto es que la LIPPJMA no contiene referencia alguna al régimen de medidas cautelares en relación con los procedimientos de incidencia ambiental, por lo que habrá de estarse a las previsiones contenidas en la LJCA, en sus artículos 129 y ss.

Sobre las garantías financieras que debe facilitar el recurrente, tales como fianzas o asunción de los daños derivados de la medida cautelar, el TJUE admite tal posibilidad al entender que no se opone directamente a que el coste no sea prohibitivo, siempre que tal contracautela venga exigida por la legislación nacional, correspondiendo al juez cerciorarse del riesgo económico que para el demandante supone a la hora de apreciar que el proceso no conlleve un coste excesivamente oneroso ${ }^{55}$.

\section{EN CONCLUSIÓN}

En resumen, tras los veinte años del Convenio de Aarhus, el acceso a la justicia ambiental no ha sido objeto de modificación, más allá de su concreción jurisprudencial. Ante la falta de una directiva o reglamento comunitario, en el ámbito de la Unión Europea son los Estados miembros los que, de acuerdo con el Convenio de Aarhus, establecen según su legislación interna el acceso a la justicia en materia ambiental, ya sea por infracción de los derechos de información y participación o por las vulneraciones de la legislación ambiental general.

En el caso de España, la cuestión de la legitimación no es problemática, dado que, de acuerdo con la interpretación amplia del artículo 19 LJCA y con la acción

${ }^{55}$ STJUE, de 13 de febrero de 2014, asunto C-530/11, Comisión c. Reino Unido. 
pública reconocida a las ONG ambientales en el artículo 22 LIPPJMA con los requisitos del artículo 23 , pocos y anecdóticos son los supuestos en que esta legitimación no es reconocida. El reconocimiento de una acción pública no hubiese cambiado el panorama; el medio ambiente no tiene quien lo defienda, salvo las citadas ONG y las personas físicas o jurídicas cuyos derechos o intereses legítimos puedan verse afectados por una decisión o proyecto con incidencia ambiental, confundiéndose en muchos casos la tutela de los intereses ambientales con intereses particulares que tratan de defenderse so pretexto de la protección ambiental. Por lo tanto, nada aportaría el reconocimiento de una acción pública ambiental más allá de la posible defensa de la legalidad, como ocurre en el ámbito urbanístico, porque quien no tiene un interés legítimo no recurrirá, con excepción de las ONG ambientales, que son las que defienden el interés legítimo colectivo ambiental.

Como ya he señalado, defender el medio ambiente, además, cuesta tiempo y, sobre todo, puede costar dinero. Los verdaderos obstáculos de la justicia ambiental radican en los costes económicos, que ya se van levantando a favor de las ONG al reconocérseles el beneficio de la justicia gratuita y la posible elusión de las garantías o cauciones exigibles ante la posible estimación de las medidas cautelares que, en su caso, soliciten, generalmente la suspensión. No obstante, el riesgo de asumir costes prohibitivos sigue siendo alto, constituyendo un claro elemento disuasorio para ejercer cualquier acción en defensa del interés ambiental.

Las posibles soluciones, alineándome con lo ya señalado por PEÑALVER I CABRÉ ${ }^{56}$ y por SANCHIS MORENO, SALAZAR ORTUÑO Y RUIZ MACIÁ ${ }^{57}$, podrían ser el establecimiento de un régimen especial de condena en costas por el que se aplicaran el criterio de vencimiento cuando las pretensiones son estimadas (total o parcialmente) y el de temeridad o mala fe cuando son desestimadas; y una regulación especial de las fianzas para la adopción de medidas provisionales o para la ejecución provisional de sentencias, de forma que el coste no sea prohibitivo.

${ }^{56}$ PEÑALVER I CABRÉ, "El derecho..." cit., p. 2352.

${ }^{57}$ SANCHIS MORENO, F., SALAZAR ORTUÑO, E. y RUIZ MACIÁ, G., Democracia ambiental y acceso a la justicia. La aplicación del Convenio de Aarhus en España, AJA y Fundación Biodiversidad, 2009, pp. 48 y 49. 
En definitiva, las propuestas para lograr una defensa ambiental adecuada van en el sentido de superar las claras limitaciones económicas que se plantean en no pocos casos a las ONG ambientales para un eficaz acceso a la justicia ambiental.

\section{BIBLIOGRAFÍA}

BERBEROFF, D., 'La tutela judicial 'ambiental' efectiva a la luz de la Ley 21/2013, de 9 de diciembre, de evaluación ambiental", Revista Urbanismo, 1 de marzo de 2014.

CARBONELL PORRAS, E., "Intereses colectivos en la jurisdicción contenciosoadministrativa", Intereses colectivos y legitimación activa, Aranzadi, Pamplona, 2014.

DEL SAZ CORDERO, S., "La influencia del Convenio de Aarhus en el sistema de tutela contencioso-administrativa del Derecho alemán. Comentario a la jurisprudencia reciente del Tribunal de Justicia de la Unión Europea sobre el acceso a la justicia de las ONG ambientales. Asuntos Trianel (C-115/09) y Oso pardo (C-240/09)", Revista de Administración Pública, núm. 188, 2012.

DORESTE HERNÁNDEZ, J., "Comentario al Auto de 22 de abril de 2013, del TSJ de Extremadura", Actualidad Jurídica Ambiental, julio de 2013.

- "El principio de precaución, Convenio de Aarhus y las medidas cautelares en el procedimiento contencioso-administrativo: Comentario de los autos de 4 de enero y 9 de marzo de 2017, de la sección segunda de la sala de lo contenciosoadministrativo del Tribunal Superior de Justicia de Canarias", Actualidad Jurídica Ambiental, núm. 69, 5 de junio de 2017.

EBBESSON, J., "Information, Participation and Access to Justice: the model of the Aarhus Convention", Joint UNEP-OHCHR Expert Seminar on Human Rights and the Environment, Background, Paper No. 5, Ginebra, 2002.

ECEIZABARRENA, X., "Participación y acceso a la justicia ambiental: el Convenio de Aarhus de 1998", Revista Aranzadi de Derecho Ambiental, núm. 1, 2002. 
EMBID IRUJO, A., "El acceso a la justicia ambiental en la jurisprudencia del Tribunal de Justicia de la Unión Europea", Revista Vasca de Administración Pública, núm. 99-100, 2014.

GARCÍA ÁLVAREZ, G., "Acceso a la información, participación y acceso a la justicia en cuestiones ambientales", Transparencia, participación y Administración Pública en el s. XXI, Revista Aragonesa de Administración Pública, 2013 (Monografías).

GARCÍA URETA, A., "Aspectos sobre el acceso a la justicia en el Convenio de Aarhus y su incidencia en el Derecho comunitario", Ingurugiroa eta Zuzenbidea, núm. 3, IVAP-Bilbao, 2005.

- "Acceso a la justicia y costes procesales: Comentario a la Sentencia del TJUE (Sala Cuarta) de 11 de abril de 2013 (Asunto C-260/11, the Queen, a instancias de: David Edwards, Lilian Pallikaropoulos v. Environment Agency, First Secretary of State, Secretary of State for Environment", REDA, 160, 2013.

GONZÁLEZ BONDÍA, A., "La regulación comunitaria del acceso a la información, la participación pública y el acceso a la justicia en materia de medio ambiente en sus estados miembros", Pigrau Solé, A. (dir.), Acceso a la información, participación pública y acceso a la justicia en materia de medio ambiente: diez años del Convenio de Aarhus, Atelier, Barcelona, 2007.

HERNÁNDEZ ARAYA, N. A., "Barreras económicas en el acceso a la justicia ambiental en España”, Revista Aranzadi de Derecho Ambiental, núm. 36, 2017. JORDANO FRAGA, J., La protección del derecho a un medio ambiente adecuado, Bosch, Barcelona, 1995.

- "El proceso de afirmación del medio ambiente como interés público prevalente o la tutela ambiental cautelar efectiva: la suspensión de los actos administrativos por razón de la protección del medio ambiente en la jurisprudencia del TS", Revista de Administración Pública, núm. 145, 1998.

- "Análisis de la Ley 27/2006 en cuanto al acceso a la justicia, en especial, el principio de legitimación en los contenciosos ambientales", Lozano Cutanda, B. (dir.), Examen de la nueva Ley de acceso a la información, participación pública 
y acceso a la justicia en materia de medioambiente, Estudios de Derecho Judicial, 137, CGPJ, Madrid, 2008.

JUSTE RUIZ, José y SALAZAR ORTUÑO, Eduardo, "Incumplimiento por parte de España de las obligaciones del convenio de Aarhus: comunicación ACCC/C/2008/24, el caso 'senda de Granada' en Murcia”, Revista Aranzadi de Derecho Ambiental, 18, 2010.

LOPERENA ROTA, D., Los principios del derecho ambiental, IVAP-Civitas, Madrid, 1998.

LOPERENA ROTA, D. y BALLESTEROS PINILLA, G., "El ejercicio de acciones en el orden contencioso-administrativo en defensa del medio ambiente", Revista Jurídica de Castilla y León, núm. 26, 2012.

LÓPEZ SÁNCHEZ, J., "La legitimación procesal en materia de medio ambiente", Embid Irujo, A. (dir.), El derecho a un medio ambiente adecuado, lustel, Madrid, 2008.

LOZANO CUTANDA, Blanca (dir.), Examen de la nueva Ley de acceso a la información, participación pública y acceso a la justicia en materia de medioambiente, Estudios de Derecho Judicial, 137, CGPJ, Madrid, 2008.

MARTÍN MATEO, R., "La problemática del accionariado popular", Revista de Estudios de la Vida Local, núm. 179, 1973.

NOGUEIRA LÓPEZ, A., "Pack Premium o pack básico. ¿Ordenamiento ambiental dual?", Revista Aranzadi de Derecho Ambiental, núm. 38, 2017.

ORTEGA BERNARDO, J., “¿Quién ha apostado por la efectiva implantación del derecho de acceso a la justicia a favor de las organizaciones no gubernamentales en defensa del medio ambiente?", Actualidad Jurídica Ambiental, núm. 6, 2011.

PEÑALVER I CABRÉ, A., "Nuevos instrumentos para la aplicación de la legislación ambiental ante la inactividad administrativa (de las acciones ciudadanas citizen suits, al Convenio de Aarhus)", Revista de Administración Pública, núm. 172, 2007.

- "Novedades en el acceso a la justicia y a la tutela administrativa en asuntos ambientales", Pigrau Solé, A. (dir.), Acceso a la información, participación pública 
y acceso a la justicia en materia de medio ambiente: diez años del Convenio de Aarhus, Atelier, Barcelona, 2008.

- "El derecho humano al medio ambiente y su protección efectiva", Revista Vasca de Administración Pública, núm. 99-100.

- La defensa de los intereses colectivos en el contencioso-administrativo: legitimación y limitaciones económicas, Aranzadi, Pamplona, 2016.

- "Acceso a la justicia ambiental: aspectos principales de la jurisprudencia contencioso-administrativa", Observatorio de políticas ambientales, 2017, CIEDA-Ciemat, Madrid, 2017.

PERNAS GARCÍA, J. J., "La aprobación o convalidación por norma con rango de Ley de proyectos sometidos a evaluación ambiental y su control de validez a la luz de la jurisprudencia del TJUE", Revista Vasca de Administración Pública, núm. 104, 2016.

PIGRAU SOLÉ, A. (dir.), Acceso a la información, participación pública y acceso a la justicia en materia de medio ambiente: diez años del Convenio de Aarhus, Atelier, Barcelona, 2008.

PIGRAU SOLÉ, A. y BORRÁS PENTINAT, S., "Diez años del Convenio de Aarhus, sobre el acceso a la información, participación pública y acceso a la justicia en materia de medio ambiente", Pigrau Solé, A. (dir.), Acceso a la información, participación pública y acceso a la justicia en materia de medio ambiente: diez años del Convenio de Aarhus, Atelier, Barcelona, 2008.

PLAZA MARTÍN, C., Derecho Ambiental de la Unión Europea, Tirant lo Blanch, Valencia, 2005.

RAZQUIN LIZARRAGA, J. A., "Las medidas cautelares en el proceso Contencioso-Administrativo respecto del medio ambiente en la reciente jurisprudencia del Tribunal Supremo", Revista Aranzadi Doctrinal, núm. 3, 2010.

RAZQUIN LIZARRAGA, J. A. y RUIZ DE APODACA ESPINOSA, A., Información, participación y acceso a la justicia en materia ambiental. Comentario sistemático de la Ley 27/2016, de 18 de julio, Aranzadi, Pamplona, 2007. 
REVUELTA PÉREZ, I., "Comentario a la STJUE de 15 de marzo de 2018", Actualidad Jurídica Ambiental, abril de 2018.

RUIZ DE APODACA ESPINOSA, A., "La acción pública ambiental: una necesidad parcialmente satisfecha por la Ley 27/2006, de 18 de julio", Revista Aranzadi de Derecho ambiental, núm. 11, 2007.

SALAZAR ORTUÑO, E., "Implicaciones del Convenio de Aarhus en la legislación sobre acceso a la justicia de los estados: la Sentencia 'Trianel' del Tribunal de Justicia de la Unión Europea de 12 de mayo de 2011, C-115/09", Revista Aranzadi de Derecho Ambiental, núm. 23, 2012.

SANCHIS MORENO, F., Guía sobre el acceso a la Justicia Ambiental. Convenio de Aarhus, Consejo General de la Abogacía Española y Asociación para la Justicia Ambiental-ELAW España, 2007.

SANTAMARÍA ARINAS, R. J., "Leyes singulares, tutela judicial efectiva y recepción de la doctrina Boxus por el Tribunal Constitucional español", Revista de Administración Pública, núm. 193, 2014.

VALENCIA MARTÍN, G., Jurisprudencia constitucional y medio ambiente, Aranzadi, Pamplona, 2017. 